\title{
Effect of Yerba Mate and Silk Fibroin Nanoparticles on the Migration Properties in Ethanolic Food Simulants and Composting Disintegrability of Recycled PLA Nanocomposites
}

\author{
Freddys R. Beltrán ${ }^{1,2}{ }^{\oplus}$, Marina P. Arrieta ${ }^{1,2, *}$, , Diego Elena Antón ${ }^{1}$, Antonio A. Lozano-Pérez ${ }^{3}{ }^{\circledR}$, José L. Cenis ${ }^{3}$, \\ Gerald Gaspar ${ }^{1,2}$, María U. de la Orden ${ }^{2,4}$ and Joaquín Martínez Urreaga ${ }^{1,2}$ \\ 1 Departamento de Ingeniería Química Industrial y Medio Ambiente, Universidad Politécnica de Madrid, \\ E.T.S.I. Industriales, 28006 Madrid, Spain; f.beltran@upm.es (F.R.B.); d.elena@alumnos.upm.es (D.E.A.); \\ geraldmanuel.gaspar@upm.es (G.G.); joaquin.martinez@upm.es (J.M.U.) \\ 2 Grupo de Investigación Polímeros Caracterización y Aplicaciones (POLCA), Madrid, Spain; mariula@ucm.es \\ 3 Depertamento de Biotecnología, Genómica y Mejora Vegetal, Instituto Murciano de Investigación y Desarrollo \\ Agrario y Alimentario (IMIDA), 30150 Murcia, Spain; abel@um.es (A.A.L.-P.); josel.cenis@carm.es (J.L.C.) \\ 4 Deparamento de Química Orgánica, Facultad de Óptica y Optometría, Universidad Complutense de Madrid, \\ 28037 Madrid, Spain \\ * Correspondence: m.arrieta@upm.es; Tel.: +34-910-677-301
}

check for updates

Citation: Beltrán, F.R.; Arrieta, M.P.; Elena Antón, D.; Lozano-Pérez, A.A.; Cenis, J.L.; Gaspar, G.; de la Orden, M.U.; Martínez Urreaga, J. Effect of Yerba Mate and Silk Fibroin Nanoparticles on the Migration Properties in Ethanolic Food Simulants and Composting Disintegrability of Recycled PLA Nanocomposites. Polymers 2021, 13, 1925. https://doi.org/10.3390/ polym 13121925

Academic Editor: Alexey Iordanskii

Received: 16 May 2021

Accepted: 5 June 2021

Published: 10 June 2021

Publisher's Note: MDPI stays neutral with regard to jurisdictional claims in published maps and institutional affiliations.

Copyright: (c) 2021 by the authors. Licensee MDPI, Basel, Switzerland. This article is an open access article distributed under the terms and conditions of the Creative Commons Attribution (CC BY) license (https:// creativecommons.org/licenses/by/ $4.0 /)$

\begin{abstract}
The main objective of the present research is to study the effect of the incorporation of low amounts of silk fibroin nanoparticles (SFNs) and yerba mate nanoparticles (YMNs) on the migration phenomenon into ethanolic food simulants as well as on the disintegrability under composting conditions of mechanically recycled polylactic acid (PLA). Recycled PLA was obtained under simulated recycling conditions by melt processing virgin PLA into films and further subjecting them to an accelerated aging process, which involved photochemical, thermal, and hydrothermal aging steps followed by an intense washing step. SFNs were extracted from Bombyx mori cocoons and YMNs from yerba mate waste. Then, recycled PLA was melted, reprocessed, and reinforced with either $1 \%$ wt. of SFNs or YMNs, by melt extrusion, and further processed into films by compression molding. The obtained nanocomposites were exposed to ethanolic food simulants (ethanol 10\% $v / v$, simulant A and ethanol 50\% $v / v$, simulant D1) and the structural, thermal, and mechanical properties were studied before and after the exposure to the food simulants. The migration levels in both food simulants were below the overall migration limits required for food contact materials. The materials were disintegrated under simulated composting conditions at the laboratory scale level and it was observed that the nanoparticles delayed the disintegration rate of the recycled PLA matrix, but nanocomposites were fully disintegrated in less than one month.
\end{abstract}

Keywords: poly(lactic acid); nanocomposites; mechanical recycling; silk fibroin; yerba mate; migration; composting

\section{Introduction}

Poly(lactic acid) (PLA) is one of the most established bioplastics in the market due to its applications in industries such as the biomedical, automotive, and 3D printing industries and especially in the food packaging field [1,2]. PLA is an aliphatic polyester that has been proposed as an alternative with a lower environmental impact to fossil-fuel-based and non-biodegradable plastics, since it is produced from renewable resources such as corn, potato, and sugar beet [3,4] and is compostable [5,6]. Despite the environmental advantages of PLA, its growing production (680 kT forecasted for 2024 [7]) and high consumption in short-term applications $[5,6]$ might cause some problems, mainly related to the management of the wastes generated after its use.

PLA is a biodegradable material; however, newer grades are very resistant and only biodegradable under industrial composting conditions, i.e., approximately $58{ }^{\circ} \mathrm{C}$, a relative 
humidity of $60 \%$, a $\mathrm{pH} \cong 7.5$, a $\mathrm{C} / \mathrm{N}$ relationship between $20: 1$ and $40: 1$, and proper aeration $[8,9]$. Such conditions are not available under environmental conditions such as in landfills. Thus, inadequate management of PLA wastes could lead to their accumulation in the environment, with the negative impact it entails [10,11]. Furthermore, this linear use and disposal of valuable materials strongly disagrees with the circular economy approach proposed by the European Commission, in which resources are recirculated and used in a more sustainable way $[12,13]$. Therefore, it is necessary to develop, and implement, valorization methods that allow us to introduce PLA and other bioplastics into the circular economy approach. In this regard, mechanical recycling could play a very important role, since it allows us to reduce the consumption of raw materials, energy, and emissions associated with the production of PLA $[14,15]$ and it also allows us to reduce the amount of PLA wastes in landfills.

Although mechanical recycling comes along with several advantages from an environmental point of view, it also poses several challenges, from both logistic and technical points of view. Nowadays, bioplastics are considered as contaminants in plastics recycling streams, since they cause a decrease in the performance of other plastics [16,17]. Therefore, it is necessary to adapt the current collection and sorting system to introduce a PLA stream. From a technical point view, previous studies have reported that mechanical recycling causes a decrease in the performance of PLA-based materials due to the degradation of the polymer [18], which negatively affects the recyclability of the material. In this regard, several methods have been proposed to improve the properties of mechanically recycled PLA, such as the use of chain extenders and crosslinking agents $[19,20]$, the application of thermal treatments [21], and addition of inorganic [22] and organic fillers [23,24]. In the food packaging field, particular attention has been paid to PLA-based nanocomposites, since nanofillers lead to an improvement in the PLA's thermomechanical and barrier performance, which are very important for packaging processing and manufacturing, as well as for the intended use [6,25].

It is worth noting that the addition of organic fillers coming from renewable resources could be an interesting method for the improvement of the properties of PLA due to the renewable origin, availability, low cost, and biodegradability of such fillers. Nanoparticles extracted from renewable resources (e.g., crops, arthropods) as well as those coming from agro-food wastes are of particular interest for sustainable materials within the frame of a circular economy approach. In this context, PLA has been widely blended with lignocellulosic nanoparticles as well as protein-based nanoparticles. For instance, the incorporation of lignocellulosic nanoparticles extracted from waste of yerba mate (Ilex paraguariensis), a commonly consumed infusion in South America, into a PLA matrix has proven to be an effective way to increase the crystallization rate of PLA, leading to an improvement in the mechanical performance of the final nanocomposites [26]. Yerba mate is rich in methylxanthines (caffeine and theobromine), but the well-known properties of yerba mate are attributed to its rich composition in bioactive substances such as phenolic compounds (e.g., lignin, caffeic acid, and chlorogenic acid), flavonoids (e.g., catechin, quercetin, rutin, and kaempferol), saponins, tannins, and some vitamins (e.g., C, B1, and B2) [27,28]. The use of yerba mate waste for the extraction of lignocellulosic nanoreinforcements with antioxidant activity has been shown to be an effective way to revalorize such waste and improve the thermal stability of PLA [26]. Interestingly, silk fibroin (SF), a natural biopolymer, also showed the ability to promote the crystallization of PLA-based materials, improving the mechanical and barrier performance of the final nanocomposites [29]. Silk fibroin is a fibrous protein obtained from Bombyx mori cocoons and has been used by the textile industry for more than 8500 years [30] due to its excellent physical properties, such as light weight, high mechanical strength, flexibility, and luster. Over the last few decades, a wide range of new applications have been developed based on its biocompatibility, biodegradability, and non-immunogenicity, becoming an outstanding candidate for biomedical uses [31]. Additionally, in previous works the addition of small amounts (e.g., $1 \mathrm{wt} . \%)$ of lignocellulosic nanoparticles extracted from yerba mate [23] as well as silk fibroin nanoparticles [24] 
produced an improvement in the overall properties of mechanically recycled PLA mainly because a good dispersion of the nanoparticles into the polymeric matrix was achieved. Meanwhile, the incorporation of $3 \mathrm{wt}$ \% of yerba mate nanoparticles tend to aggregate [23]. However, the control of the release of potentially migrant compounds from the packaging material to the foodstuff is of fundamental importance in PLA-based food packaging materials. In previous works, it was observed that the low-molecular-weight compounds, such as plasticizers, favor the release of components from the PLA-based packaging materials to the foodstuff $[32,33]$. Thus, in the case of mechanically recycled PLA materials, in which the polymer undergoes degradation during the service and recycling process leading to a reduction in the molecular weight with the formation of shorter polymeric chains, an increase in the migration phenomenon is expected. Nevertheless, different results were obtained for recycled PLA-based nanocomposites reinforced with yerba mate and silk fibroin nanoparticles in which the homogeneous distribution of nanoparticles into the polymeric matrix leads to materials with improved overall performance [23,24], and thus with potentially more complex migration processes.

Consequently, the main objective of the present research is to study the effect of the addition of low amounts (1 wt.\%) of either YMNs or SFNs on the migration phenomenon of recycled PLA exposed to two ethanolic food simulants: a hydrophilic food simulant (food simulant A: $10 \% v / v$ ethanol solution) and a fatty food simulant (simulant D1: 50\% $v / v$ ethanol solution) as well as the effect of such nanoparticles on the bionanocomposites' disintegration under composting conditions. This would allow us to obtain information regarding the use of these nanocomposites in the food packaging field as well as provide a sustainable end-of-life option to these recycled PLA-based nanocomposites after their useful life.

\section{Materials and Methods}

\subsection{Materials}

A commercial grade of PLA designed for packaging applications, the Ingeo ${ }^{\mathrm{TM}} 2003 \mathrm{D}$, was purchased from NatureWorks (Minnetonka, MN, USA). This grade presents a specific viscosity of 1.24 and a melt-flow rate of $6 \mathrm{~g} / 10 \mathrm{~min}\left(210^{\circ} \mathrm{C}, 2.16 \mathrm{~kg}\right)$. The yerba mate (Ilex paraguariensis) residues were collected after consumption of a yerba mate infusion in our laboratory. Bombyx mori cocoons were supplied by Instituto Murciano de Investigación y Desarrollo Agrario y Alimentario (IMIDA, Murcia, Spain). All chemicals and solvents were purchased from Merck (Madrid, Spain), were of analytical grade, and were used without further purification, unless otherwise specified.

\subsection{Extraction of Yerba Mate Nanoparticles (YMN)}

The extraction of the yerba mate nanoparticles from yerba mate waste was conducted according to the procedure developed by Arrieta et al. [26], which is shown in Figure 1: (i) the yerba mate waste was firstly dried in an oven $\left(24 \mathrm{~h}\right.$ at $\left.60^{\circ} \mathrm{C}\right)$; (ii) $100 \mathrm{~mL}$ of distilled water was added to $6 \mathrm{~g}$ of the dry yerba mate residue and heated under reflux up to $100{ }^{\circ} \mathrm{C}$ and under continuous stirring; (iii) the solid residue was separated by filtration, and the extracted yerba mate solution was filtered again using Whatman Grade 41 filter paper; and (iv) the filtered solution was then frozen and freeze-dried to obtain the YMN powder. Dynamic light scattering (DLS) measurements showed that the YMNs in solution present an average size of $93 \mathrm{~nm}$ (Figure S1a) and the YMNs in powder present an average size of $497 \mathrm{~nm}$ (Figure S1a) due to the fact that YMNs tend to agglomerate during the freeze-drying process [23] as can be seen in the TEM image (Figure S1b). 


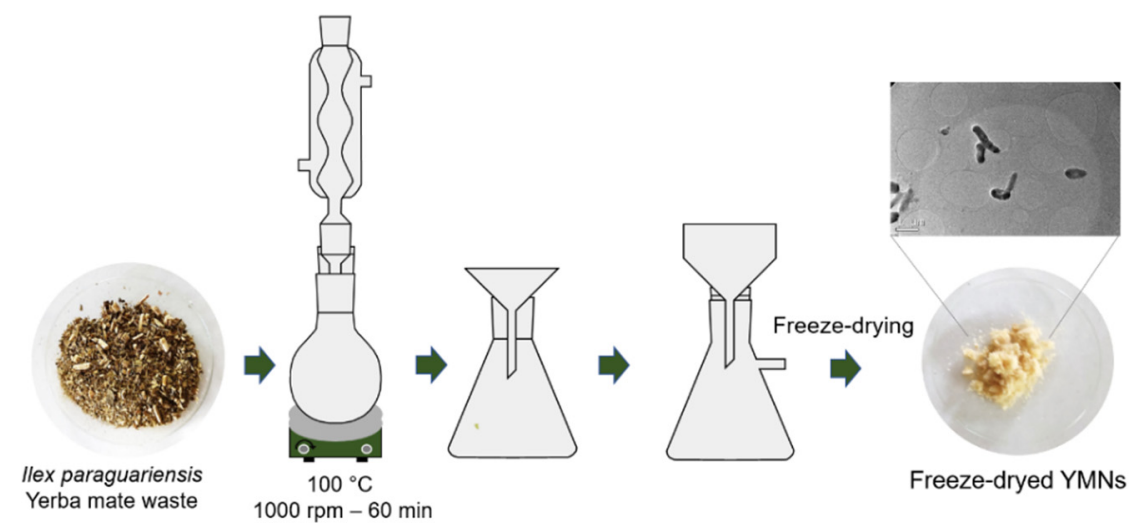

Figure 1. Schematic representation of the yerba mate nanoparticles (YMN)' extraction from yerba mate infusion wastes.

\subsection{Obtention of the Silk Fibroin Nanoparticles (SFN)}

The silk fibroin nanoparticles were prepared by rapid desolvation of the freshly prepared silk fibroin aqueous solution in absolute ethanol, following the procedure described previously by Lozano-Pérez et al. [34]. In brief, degummed silk fibroin [35] was dissolved in Ajisawa's solvent system at $65^{\circ} \mathrm{C}$ for $3 \mathrm{~h}$ [36], filtered, and dialyzed for $48 \mathrm{~h}$ against distilled water with several changes in order to remove salts and alcohol. Then, the aqueous silk fibroin solution was dripped on ethanol under gentle stirring, resulting in the formation of the nanoparticles by rapid desolvation. The resultant suspension was stirred for $2 \mathrm{~h}$, until the nanoparticles were stabilized, and then were recovered by centrifugation at $12,000 \times g$ for $15 \mathrm{~min}$ and $8{ }^{\circ} \mathrm{C}$ in an Eppendorf 5810R centrifuge (Eppendorf AG, Hamburg, Germany) equipped with an F-34-6-38 rotor, repeatedly washed $(3 \times)$ with ultrapure water $(18 \mathrm{M} \Omega \cdot \mathrm{cm}$, from a Purelab Flex 2 ultrapure water Type I system, ELGA, High Wycombe, UK), and finally dispersed in ultrapure water by using high-power ultrasounds for $1 \mathrm{~min}$ at $10 \%$ of amplitude in a Branson SFX 550 Digital Sonifier equipped with a 1/8" tapered microtip (Branson Ultrasonics Corp, Ridge Road Brookfield, CT, USA) (Figure S2). The resulting dispersion was then freeze-dried at $-55^{\circ} \mathrm{C}$ and $0.05 \mathrm{mbar}$ for $72 \mathrm{~h}$ in a Christ Alpha 1-2 LDplus freeze-dryer (Martin Christ Gefriertrocknungsanlagen GmbH, Osterode am Harz, Germany) to obtain the SFNs as a white powder. A scheme of the process can be seen in Figure 2.

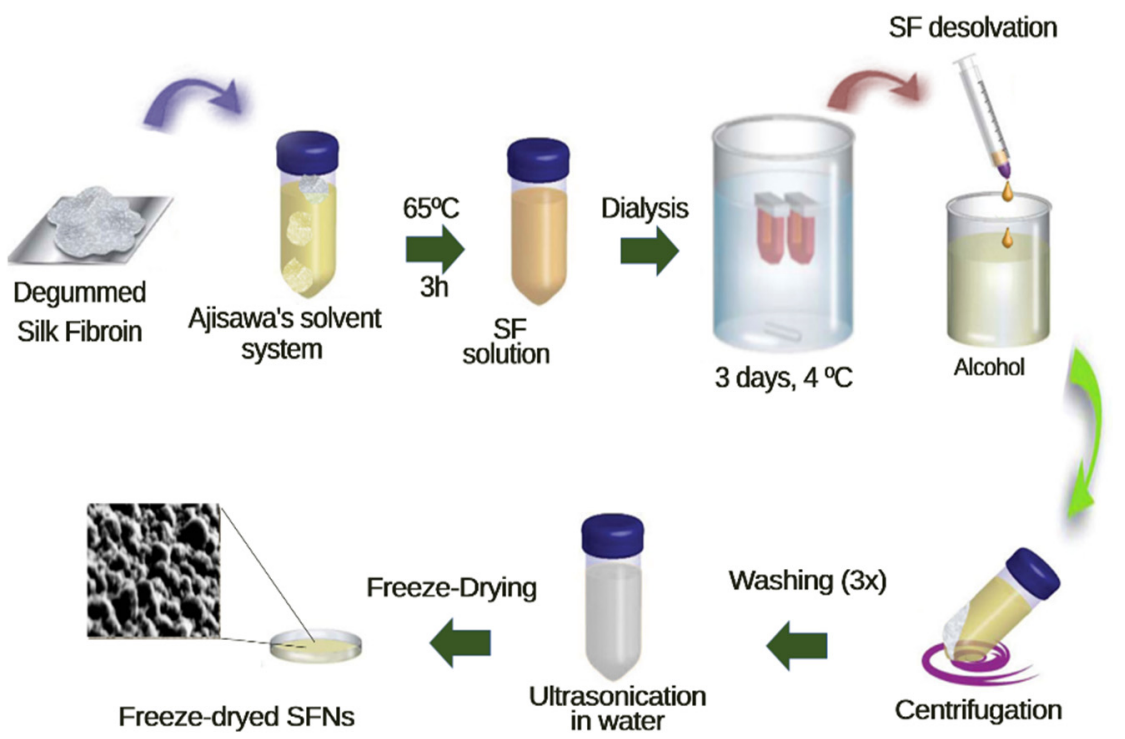

Figure 2. Schematic representation of the silk fibroin nanoparticles (SFN) preparation. 


\subsection{Mechanical Recycling of PLA and Preparation of the Nanocomposites}

Figure 3 shows the schematized mechanical recycling process along with the preparation of the nanocomposites. The number average molecular weight $(\mathrm{Mn})$ and polydispersity indexes (PDI) of PLA pellets as well as PLA and recycled PLA film were measured by Gel permeation chromatography (GPC) using a Waters Division Millipore chromatographic system (Milford, MA, USA) equipped with a Waters 2414 refractive index detector and Styragel columns and using THF (HPLC grade, Fisher Scientific, Madrid, Spain) $\left(1 \mathrm{~mL} \mathrm{~min}^{-1}\right.$ flow rate) as an eluent at $40{ }^{\circ} \mathrm{C}$. The calibration was made with polystyrene standards.

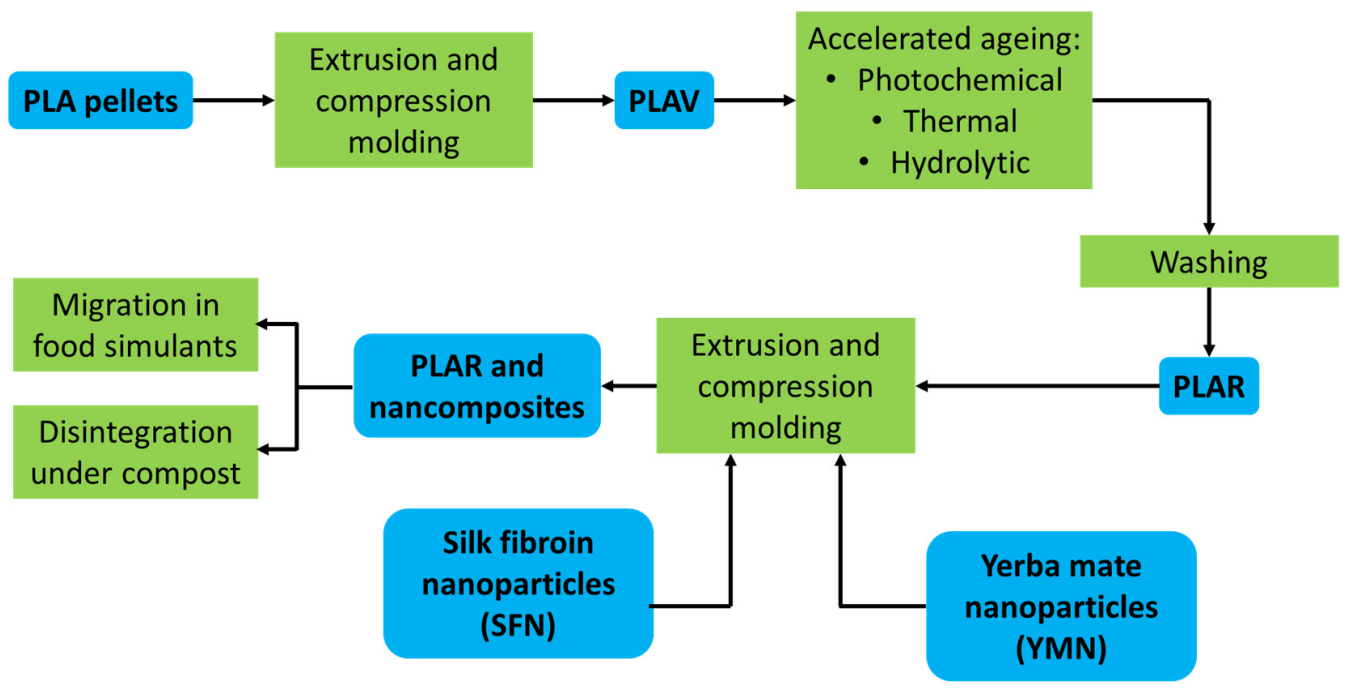

Figure 3. Scheme of the recycling of poly(lactic acid) (PLA) and the manufacturing of nanocomposites.

In a first stage, PLA pellets were thoroughly dried $\left(2 \mathrm{~h}\right.$ at $85{ }^{\circ} \mathrm{C}$ and under vacuum) $(\mathrm{Mn}=109,000$ and PDI $=1.6)$ and melt-processed in a Rondol Microlab twin screw microcompounder (Nancy, France) (L/D ratio $=20)$, at $60 \mathrm{rpm}$, with the following temperature profile from hopper to die: $125-165-190-190-180{ }^{\circ} \mathrm{C}$. The resulting material was then transformed into films (thickness $=200 \pm 10 \mu \mathrm{m}$ ) using a hot plate press (IQAP-LAP, Barcelona, Spain) at $190{ }^{\circ} \mathrm{C}$ for $5 \mathrm{~min}$. In a second stage, the obtained films were subjected to an accelerated aging protocol, including $40 \mathrm{~h}$ of photochemical aging in an UV-CON chamber (Atlas, Mount Prospect, IL, USA) equipped with 8 F40UVB lamps, $280 \mathrm{~h}$ of thermal aging in an oven at $50{ }^{\circ} \mathrm{C}$, and $240 \mathrm{~h}$ of hydrothermal aging at $25^{\circ} \mathrm{C}$ in demineralized water. Then, the aged samples were washed at $85^{\circ} \mathrm{C}$ in a solution of $\mathrm{NaOH}(1.0 \mathrm{wt} . \%)$ and Triton X-100 (Alfa Aesar, Kandel, Germany) (0.3\%wt.) following the conditions used in previously published recycling studies [18,37]. In a third stage, the washed material was shredded and processed into recycled PLA film (PLAR, $\mathrm{Mn}=80,500$ and PDI $=1.8$ ), blended with YMNs (1 wt.\%) and SFNs (1 wt.\%), and melt-extruded to be further compression molded under the same conditions as PLAV (PLAV, $\mathrm{Mn}=92,000$ and PDI $=1.8$ ). The obtained nanocomposites showed a homogeneous distribution of the nanoparticles into the polymeric matrix (Figure S3). The obtained materials were finally subjected to migration studies in food simulants and to disintegration under composting conditions tests. Table 1 summarizes the obtained amples.

Table 1. Samples obtained after the mechanical recycling process.

\begin{tabular}{cr}
\hline Sample & Description \\
\hline PLAV & PLA films obtained from extrusion and compression molding of PLA pellets. \\
PLAR & PLAV films subjected to accelerated aging, washing, and reprocessing. \\
PLAR-SFN & PLAR with 1 wt.\% of silk fibroin nanoparticles. \\
PLAR-YMN & PLAR with 1 wt.\% of Yerba mate nanoparticles. \\
\hline
\end{tabular}




\subsection{Overall Migration Tests}

Overall migration tests of the different samples were performed in two different ethanolic food simulants [38]: simulant A, a 10\% v/v ethanol solution; and simulant D1, a $50 \% v / v$ ethanol solution (ethanol absolute, Panreac, Barcelona, Spain). The samples areas exposed to the food simulants were selected on the basis of the overall migration test standard [39]. Four specimens of $1.5 \times 1.5 \mathrm{~cm}$ were immersed in $9 \mathrm{~mL}$ of food simulant (area-to-volume ratio $=1 \mathrm{dm}^{2} / 100 \mathrm{~mL}$ ) contained in glass vials. The immersed samples were kept in an oven at $40{ }^{\circ} \mathrm{C}$ for 10 days. Then, the immersed samples were removed and thoroughly dried for characterization. Meanwhile, the glass vials were heated on a heating pan to evaporate most of the food simulant and then dried in a vacuum oven at $70^{\circ} \mathrm{C}$ for 1 day. The dry vials were weighted in a QUINTIX125D-1S analytical balance (Sartorius, Gotinga, Germany) to determine the amount of migrated material.

\subsection{Disintegration under Composting Conditions}

The different samples were disintegrated under simulated composting conditions at laboratory scale, according to the ISO 20,200 standard [40]. Specimens of $1.5 \times 1.5 \mathrm{~cm}$ were buried at 4-6 cm deep in a perforated plastic container containing solid synthetic waste. Samples were kept in textile mesh to allow for the removal of disintegrated film samples during different days of the composting test as well as to be in direct contact with the compost medium [41]. The solid synthetic waste was formed by mature compost (Compo Group, Barcelona, Spain) (10 wt.\%), sawdust (Productos Adrian, Valencia, Spain) (40 wt.\%), rabbit food (Vitakraft, Bremen, Germany) (30 wt.\%), starch (Unilever Spain, Barcelona, Spain) (10 wt.\%), sugar (Azucarera, Madrid, Spain) (5 wt.\%), corn oil (Koipe, Córdoba, Spain) (4 wt.\%), and urea (Quimipur, Madrid, Spain) (1 wt.\%). Up to $50 \mathrm{wt.} \%$ water was then added to the synthetic waste. The containers were kept under aerobic conditions at $58^{\circ} \mathrm{C}$ in an oven (Memmert $\mathrm{GmbH}$, Schwabach, Germany). Specimens were removed at 1 , 4,11 , and 17 days. The degree of disintegrability was calculated following Equation (1):

$$
\% \text { disintegration }=\frac{w_{0}-w_{t}}{w_{0}} \times 100
$$

where $w_{0}$ is the initial weight of the specimens and $w_{t}$ the weight after $t$ days buried in the composting medium.

The recovered specimens were then dried and stored under vacuum for characterization.

\subsection{Characterization Techniques}

Differential scanning calorimetry tests were conducted on a Q20 calorimeter (TA Instruments, New Castle, DE, USA) under a nitrogen atmosphere. Samples (5 mg) were put in standard aluminum pans and subjected to a first heating scan, at $5^{\circ} \mathrm{C} / \mathrm{min}$, from 30 to $180^{\circ} \mathrm{C}$; an isothermal step at $180^{\circ} \mathrm{C}$ for $3 \mathrm{~min}$; a cooling scan, at $5^{\circ} \mathrm{C} / \mathrm{min}$, from 180 to $0^{\circ} \mathrm{C}$; and an isothermal step at $0{ }^{\circ} \mathrm{C}$ for $1 \mathrm{~min}$, and a second heating scan, at $5^{\circ} \mathrm{C} / \mathrm{min}$, from 0 to $180^{\circ} \mathrm{C}$. The crystallinity degree, $X_{C}^{D S C}$, was calculated using Equation (2):

$$
X_{C}^{D S C}=\frac{\Delta H_{m}-\Delta H_{c c}}{\Delta H_{\infty}} \times 100
$$

where $\Delta H_{m}$ and $\Delta H_{c c}$ are the melting and cold crystallization enthalpies, respectively.

Fourier Transform Infrared (FTIR) spectra of the materials were recorded in a Nicolet iS10 spectrometer (Thermo Scientific, Waltham, MA, USA) equipped with a Smart iTR Attenuated Total Reflectance (ATR) accessory controlled by OMNIC Software Ver. 9.9.473. The resolution used was $4 \mathrm{~cm}^{-1}$, and 16 spectra were recorded for each sample. All the spectra were normalized at $1451 \mathrm{~cm}^{-1}$, a commonly used internal standard. The surface crystallinity degree was calculated using the $956 \mathrm{~cm}^{-1}$ absorption band according to Equation (3) [42]:

$$
X_{C}^{F T I R}=\frac{I_{0}-I_{t}}{I_{0}} \times 100
$$


where $I_{0}$ and $I_{t}$ are the intensity of the $956 \mathrm{~cm}^{-1}$ absorption band before and after the immersion in the different food simulants, respectively.

Thermogravimetric analysis of the samples was performed in a TGA2050 thermobalance (TA Instruments, New Castle, DE, USA) under a nitrogen atmosphere. Samples $\left(10 \mathrm{mg}\right.$ ) were put in a platinum crucible and heated from 40 to $800^{\circ} \mathrm{C}$ at $10^{\circ} \mathrm{C} / \mathrm{min}$.

Vickers hardness was measured in a Shimadzu Type $\mathrm{M}$ microhardness tester (Kioto, Japan) with a load of $25 \mathrm{~g}$ and a loading time of $10 \mathrm{~s}$. Each sample was measured six times.

Other techniques used for nanoparticle characterization are detailed in the supplementary information file.

\subsection{Statistical Analysis}

Significance in overall migration studies as well as in mechanical properties was analyzed using one-way analysis of variance (ANOVA) with Origin Pro 8 software SRO v8.0724 (OriginLab Corporation, Northampton, MA, USA). Comparisons between groups were made by performing a Tuckey's test with a 95\% confidence interval. Thus, the reported $p$-values were considered statistically significant at $p<0.05$.

\section{Results and Discussion}

\subsection{Migration to the Food Simulants}

Overall migration studies were conducted in food simulants A and D1 and the results after 10 contact days are shown in Figure 4. Higher migrations levels were observed in simulant D1 with respect to the same material exposed to simulant A $(p<0.05)$. With increasing the ethanol concentration from $10 \% v / v$ in Simulant A to 50\% $v / v$ in Simulant D1, higher migration values were observed in all formulations $(p<0.05)$. It is known that sorption of certain organic solvents, including ethanol, causes swelling of the PLA matrix and creates voids enlarging the gaps between molecules in the polymer structure, resulting in an increase in the free volume that further promotes the diffusion of potential migrants (additives, low-molecular-weight compounds, etc.) from the polymer to the food simulant [43-45]. Higher migration levels were observed in the PLAR sample with respect to PLAV in Simulant D1 $(p<0.05)$, in which the highest amount of ethanol promotes a higher free volume increment. This could be explained by the degradation of PLA during recycling, which generates shorter polymer chains. Migration of these low-molecularweight segments could be more easily promoted by ethanol, while more water molecules are able to diffuse into the polymeric matrix, accelerating the hydrolysis process. With regard to the nanocomposites, somewhat higher migration levels $(p>0.05)$ were observed, but it should be highlighted that all the materials presented migration levels lower than the legal overall migration limit of $60 \mathrm{mg} / \mathrm{kg}$ of food simulant [38].

\subsection{Structural Changes after Immersion in the Food Simulants}

The degradation and subsequent migration of the degradation products to the food simulant are not the only effects of ethanolic solutions on PLA matrix. Previous studies, such as those conducted by Fortunati et al. [43], Arrieta et al. [32], and IñiguezFranco et al. [44,46], have reported an increase in the crystallinity degree of PLA-based materials after immersion in ethanolic solutions at different concentrations. The structural changes of the different samples after immersion were studied by means of DSC and FTIR spectroscopy. Figure 5 shows the DSC first heating scans before immersion (a) and after the immersion in simulant A (b) and simulant D1 (c). Table 2 summarizes the DSC results of the different samples.

Figure 5 a shows that before immersion, all the samples showed the characteristic thermal transitions of PLA: (i) a glass transition between 55 and $60^{\circ} \mathrm{C}$; (ii) a cold crystallization exothermic peak above $100^{\circ} \mathrm{C}$; and (iii) a melting endotherm above $140{ }^{\circ} \mathrm{C}$. Despite the similar overall behavior of all the materials, there are some important differences between the recycled PLA-based materials and PLAV. Both Figure 5a and Table 2 show that mechanical recycling caused an important decrease in the $T_{c c}$ value of PLA, which can be 
attributed to the presence of shorter polymer chains with higher mobility, thus forming crystalline structures at lower temperatures [18,47]. Regarding nanocomposites, it is expected that nanoparticles act as nucleating agents for PLAR, decreasing $T_{\mathcal{C}}$, but this was not observed. This behavior could be ascribed to the nanoparticles hindering the movement of the molecular segments, thus countering the effect of the shorter polymer chains.

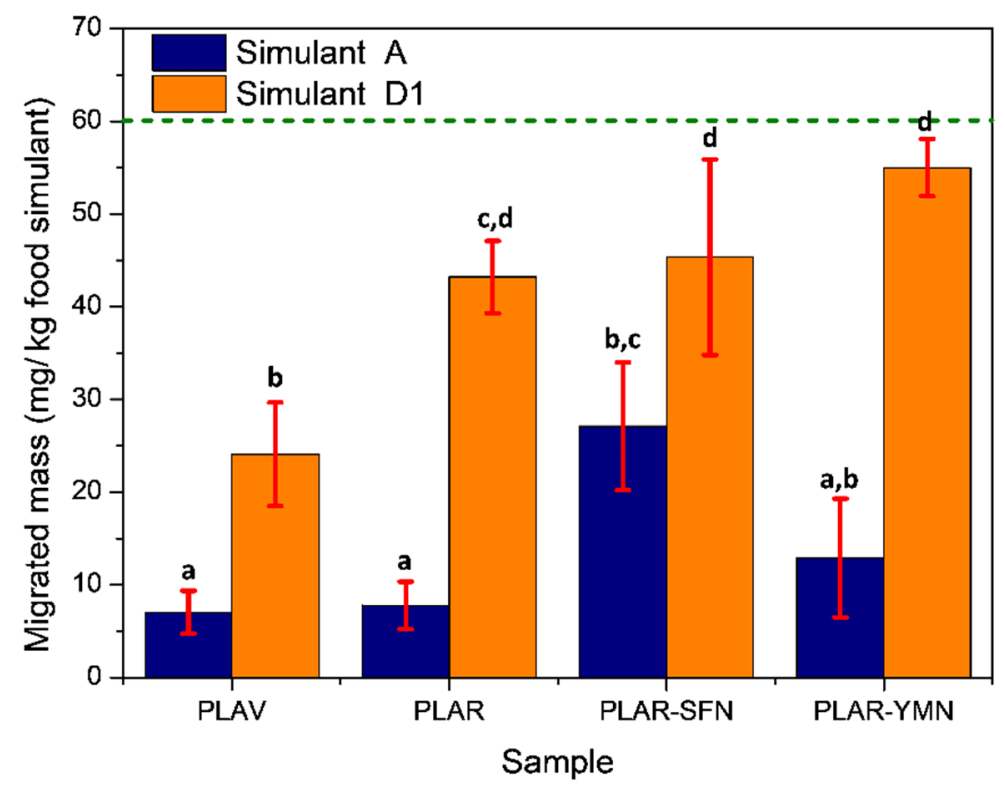

Figure 4. Overall migration of virgin poly(lactic acid) (PLAV) and recycled poly(lactic acid) (PLAR), and nanocomposites to the different food simulants A) (ethanol 10\% v/v) and D1) (ethanol 50\% v/v). The green line indicates the legal overall migration limit $\left(60 \mathrm{mg} / \mathrm{kg}\right.$ of food simulant). ${ }^{\mathrm{a}-\mathrm{d}}$ Different letters indicate statistically significant differences between formulations $(p<0.05)$.

Moreover, noticeable differences can be observed in the melting endotherms of the different samples. The recycled PLA-based materials showed two well-defined melting peaks, attributed to the melting of two different crystal size populations, while PLAV showed a single peak accompanied by a high temperature shoulder. This difference could also be explained by the presence of shorter polymer chains in the recycled materials, since their higher mobility could allow them to rearrange into less-ordered crystalline structures during heating, and then melt at a higher temperature. This mechanism has been previously reported by Di Lorenzo et al. [48] in PLA-based materials. It is also worth noting that the addition of $1 \mathrm{wt} . \%$ of the different organic nanofillers only had a limited effect on the thermal transitions of recycled PLA, as has previously been commented and also reported in the literature [23,24].

Regarding the behavior of the samples after immersion in food simulant A, Figure $5 \mathrm{~b}$ shows that, in all samples, an endothermic peak appeared in the glass transition region. This peak is ascribed to the physical aging of PLA, which consists in the slow rearrangement of polymer segments at temperatures below $T_{g}$, resulting in a reduced free volume, higher stiffness, and decreased deformability $[49,50]$. In the conditions of this experiment, the increased chain mobility, due to the plasticizing effect of water, might have increased the rate of the physical aging process of all the samples, so the peak is more intense than in the starting materials [51,52]. Table 2 shows that, after the immersion in food simulant $\mathrm{A}$, all the samples presented significantly lower $T_{c c}$ values than the non-immersed materials. This decrease in the cold crystallization temperature is related to the hydrolytic degradation of PLA, since shorter polymer chains can crystallize at lower temperatures. Figure $5 b$ and Table 2 also show that PLAV has higher Tcc values than the PLAR-based materials due to the presence of larger polymer chains. However, the nanocomposites show higher $T_{c c}$ values than PLAR. This behavior could be due to the presence of the nanoparticles limiting the movement of molecular segments, thus hindering the formation of crystalline 
domains. A similar behavior was reported in PLA-halloysite nanocomposites immersed in a phosphate buffer solution at $58{ }^{\circ} \mathrm{C}$ [53].
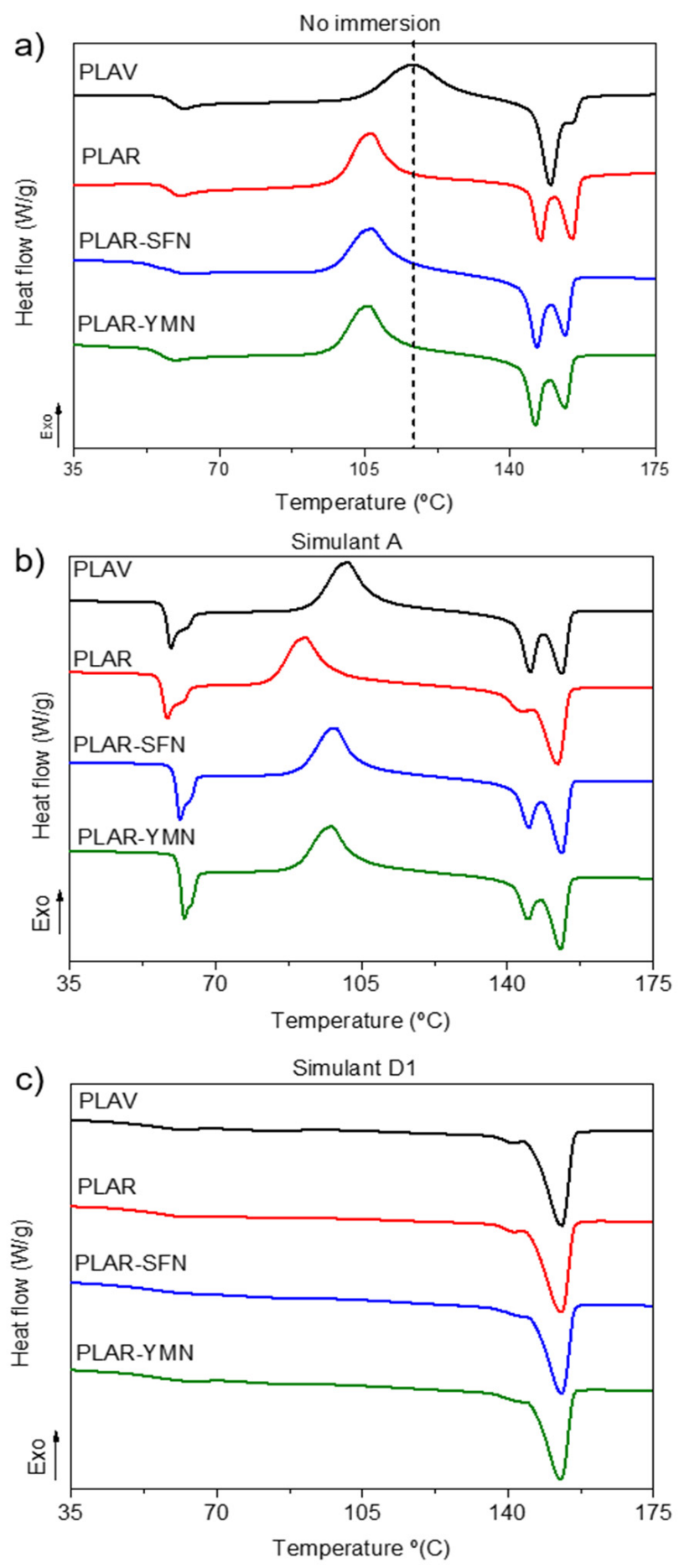

Figure 5. DSC first heating scans of the samples before (a) and after overall migration tests in food simulants: A (ethanol 10\% v/v) (b) and D1 (ethanol 50\% v/v) (c).

It can also be seen in Table 2 that all the samples showed a slight crystallization, which could be attributed both to the plasticizing effect of the water and the hydrolytic degradation of the amorphous zones of PLA [44] as well as the above-described swelling effect produced by the ethanolic solution. 
Table 2. DSC first heating results and FTIR crystallinity degree of the different samples.

\begin{tabular}{|c|c|c|c|c|c|c|c|}
\hline Sample & $\begin{array}{c}T_{g} \\
\left({ }^{\circ} \mathrm{C}\right)\end{array}$ & $\begin{array}{c}T_{c c} \\
\left({ }^{\circ} \mathrm{C}\right)\end{array}$ & $\begin{array}{c}T_{m} \\
\left({ }^{\circ} \mathrm{C}\right)\end{array}$ & $\begin{array}{c}\Delta H_{c c} \\
(\mathrm{~J} / \mathrm{g})\end{array}$ & $\begin{array}{c}\Delta H_{m} \\
(\mathrm{~J} / \mathrm{g})\end{array}$ & $\begin{array}{c}X_{C}^{D S C} \\
(\%)\end{array}$ & $\begin{array}{c}X_{C}^{F T I R} \\
(\%)\end{array}$ \\
\hline \multicolumn{8}{|c|}{ No immersion } \\
\hline PLAV & 57.7 & 116.8 & 149.9 & 25.8 & 25.9 & 0 & 0 \\
\hline PLAR & 56.9 & 106.4 & $147.5-155.2$ & 25.1 & 25.9 & 1 & 0 \\
\hline PLAR-SFNs & 55.6 & 106.6 & $146.6-153.4$ & 24.8 & 27.5 & 3 & 0 \\
\hline PLAR-YMNs & 55.2 & 105.8 & 146.2-153.4 & 25.2 & 26.4 & 1 & 0 \\
\hline \multicolumn{8}{|c|}{ After immersion in food simulant $A$} \\
\hline PLAV & 57.4 & 101.6 & $145.6-153.3$ & 24.0 & 28.4 & 5 & 0 \\
\hline PLAR & 56.4 & 91.4 & $143.9-152.1$ & 23.0 & 28.5 & 6 & 0 \\
\hline PLAR-SFNs & 58.9 & 98.7 & 145.2-153.1 & 22.5 & 27.3 & 5 & 7 \\
\hline PLAR-YMNs & 60.7 & 97.8 & $145.1-152.3$ & 21.3 & 26.0 & 5 & 0 \\
\hline \multicolumn{8}{|c|}{ After immersion in food simulant D1 } \\
\hline PLAV & 53.5 & Not shown & $141.4-153.0$ & 0 & 34.4 & 37 & 34 \\
\hline PLAR & 53.1 & Not shown & 141.4-153.0 & 0 & 32.2 & 35 & 33 \\
\hline PLAR-SFNs & 53.6 & Not shown & 153.1 & 0 & 32.6 & 35 & 31 \\
\hline PLAR-YMNs & 54.6 & Not shown & 152.8 & 0 & 32.3 & 35 & 24 \\
\hline
\end{tabular}

In the case of the samples immersed in the simulant D1, the structural changes are more drastic. Table 2 shows a slight reduction in the $T_{g}$ values, which could be due both to the severe degradation of PLA and the plasticizing effect of the ethanolic food simulants. Furthermore, it can be seen in Figure $5 \mathrm{c}$ that all the samples showed no cold crystallization peak. This behavior might indicate that all the available regions for crystallization were indeed crystallized during the immersion in the food simulant. This behavior is not uncommon in PLA-based materials immersed in aqueous solutions, as has been reported by authors such as Badía et al. [54] and Simmons et al. [55]. This significant crystallization could be related to the plasticizing effect produced by water and the swelling effect of the amorphous phase produced by ethanol, and also the severe degradation of the samples, leading to an induced crystallinity when exposed to $50 \%$ of each solvent as was pointed out by Iñiguez-Franco et al. [44,46].

Additional information about the structural changes that took place on the surface of the samples, during the immersion in food simulants, can be obtained by means of ATRFTIR spectroscopy. Figure 6 shows the region between 900 and $980 \mathrm{~cm}^{-1}$ of the ATR-FTIR spectra of PLAR before and after immersion in the different simulants. The absorption bands located at 956 and $920 \mathrm{~cm}^{-1}$ are assigned to the coupling of the stretching of the skeletal C-C bonds and the rocking of the $\mathrm{CH}_{3}$ [56]. The band located at $920 \mathrm{~cm}^{-1}$ can be correlated to the $10_{3}$ helix chain conformation characteristic of the ordered crystalline zones, while the band at $956 \mathrm{~cm}^{-1}$ can be assigned to the amorphous regions of the polymer [53,57]. As can be seen in Figure 6, the immersion in food simulants led to an increase in the absorption of the band centered at $920 \mathrm{~cm}^{-1}$, along with a decrease that centered at $956 \mathrm{~cm}^{-1}$, indicating a certain degree of crystallization, especially in the samples immersed in simulant D1. According to Meaurio el al. [42] and Beltran et al. [53], the degree of crystallinity can be estimated following the evolution of the band at $956 \mathrm{~cm}^{-1}$ Equation (3). Table 2 shows the values of crystallinity calculated with Equation (3), and it can be seen that no increase in the superficial crystallinity occurred during the immersion in food simulant A, with exception of the PLAR-SFNs nanocomposite, which showed a slight crystallization on its surface. On the other hand, Table 2 shows that all the samples immersed in food simulant D1 had a crystallization degree over $20 \%$, in good agreement with the DSC results. Nevertheless, it can be seen that the nanocomposites showed lower surface crystallinity values than the unfilled PLA samples, especially the PLAR-YMNs sample. This result suggests that the presence of the nanoparticles inhibits the formation 
of crystalline domains on the surface of the nanocomposites while the global crystallinity, measured by DSC, is not affected by both nanoparticles.

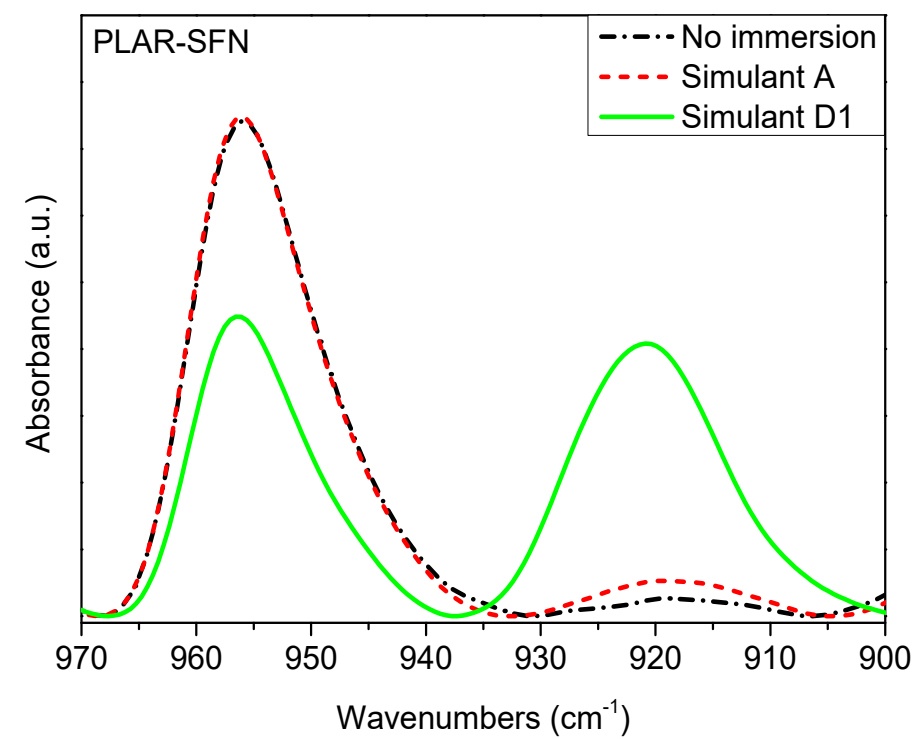

Figure 6. ATR-FTIR spectra of the recycled poly(lactic acid) and silk fibroin nanoparticle nanocomposite (PLAR-SFN) before and after immersion in the different food simulants. Region between 900 and $970 \mathrm{~cm}^{-1}$.

\subsection{Variation in the Properties of the Materials as a Result of the Immersion in Food Simulants}

As has been discussed in the previous sections, the immersion of PLA in the different food simulants could cause important structural changes that can affect the properties of the materials. Thermal stability and hardness were measured, before and after immersion, by means of dynamic TGA and microhardness measurement tests, respectively. Figure 7 and Table 3 summarize the TGA results of the different samples.
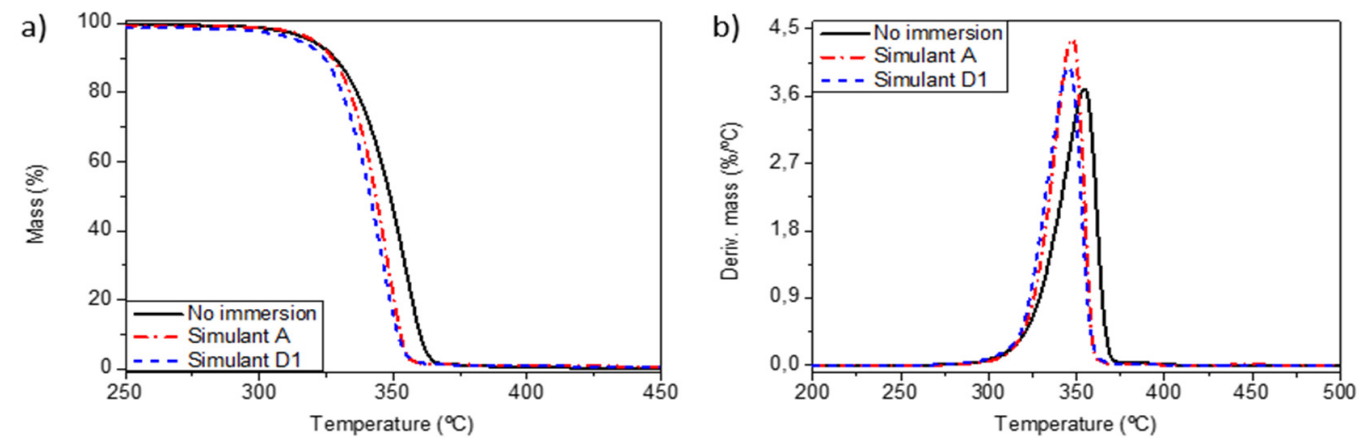

Figure 7. Weight loss (a) and derivative weight loss (b) of PLAV before and after immersion.

Figure 7 shows that PLAV presented a single-step thermal degradation process. This behavior was followed by all the materials. The $\mathrm{T}_{10}$ values shown in Table 3 point out that mechanical recycling caused a slight decrease in the thermal stability of PLA as a result of the degradation of the polymer [18]. Nevertheless, the addition of SFNs and YMNs led to a slight increase in the thermal stability of the recycled material. This improvement in the thermal stability has already been observed for PLA reinforced with both YMNs $[23,26]$ and SFNs [29]. The beneficious effect of the nanoparticles could be explained by their barrier effect, which limits the liberation of degradation products and increases the thermal stability of the polymeric matrix [24]. 
Table 3. TGA parameters of the samples before and after immersion in food simulants.

\begin{tabular}{cccc}
\hline Sample & $\begin{array}{c}\mathbf{T}_{\mathbf{1 0}} \\
\left({ }^{\circ} \mathbf{C}\right)\end{array}$ & $\begin{array}{c}\mathbf{T}_{\mathbf{5 0}} \\
\left({ }^{\circ} \mathbf{C}\right)\end{array}$ & $\begin{array}{c}\mathbf{T}_{\max } \\
\left({ }^{\circ} \mathbf{C}\right)\end{array}$ \\
\hline PLAV & \multicolumn{3}{c}{ No immersion } \\
PLAR & 328.2 & 348.9 & 354.5 \\
PLAR-SFNs & 323.1 & 350.2 & 359.5 \\
PLAR-YMNs & 331.2 & 360.4 & 370.0 \\
\hline PLAV & 326.8 & 352.6 & 359.5 \\
\hline PLAR & After immersion in simulant $\mathbf{A}$ & 347.4 \\
PLAR-SFNs & 327.3 & 343.5 & 356.0 \\
PLAR-YMNs & 323.6 & 350.8 & 362.8 \\
\hline PLLAV & 325.9 & 353.4 & 357.8 \\
\hline PLAR & 318.7 & 348.5 & 345.5 \\
PLAR-SFNs & After immersion in simulant D1 & 348.5 \\
PLAR-YMNs & 324.2 & 341.4 & 356.6 \\
\hline
\end{tabular}

Table 3 also shows that, overall, the immersion in the different ethanolic food simulants resulted in a decrease in the thermal stability of all the samples, especially in the case of the simulant D1. These results could be explained by the hydrolytic degradation of the material during the immersion, since shorter polymer chains decompose at lower temperatures. These findings are in good agreement with those reported by Fukushima et al. [58] and Beltrán et al. [59] in PLA-based materials subjected to severe hydrolytic degradation conditions at $58{ }^{\circ} \mathrm{C}$. Moreover, it is expected that the higher amount of ethanol in this food simulant extracts higher amounts of migrants from the packaging materials, leading to a higher reduction in the thermal stability. In fact, the reduction in the thermal stability was particularly marked in the YMN-based nanocomposite immersed in the food simulant D1. This behavior can be ascribed to a higher extraction of YMNs by the ethanol fraction followed by a solubilization effect of YMNs in the food simulant D1. In fact, ethanolic solutions are used to extract active components from yerba mate [60]

The mechanical properties of the samples could also be affected by the structural changes that take place during the immersion in the different food simulants. Figure 8 shows the Vickers hardness values of the different samples before and after the immersion in the different food simulants. The mechanical recycling process led to a slight, but not significant $(p>0.05)$, decrease in the hardness of PLA. This behavior has been reported in previous studies, and it is related to the degradation of the polymer during the accelerated aging, washing, and melt reprocessing $[18,61]$. However, the addition of both silk fibroin and yerba mate nanoparticles led to a significant increase $(p<0.05)$ in the hardness of recycled PLA. The reinforcing character of these nanoparticles has already been pointed out in previous studies [23,24].

Regarding the behavior of the samples immersed in both food simulants, Figure 8 shows a significant increase in the Vickers hardness after the immersion for all the materials $(p<0.05)$. These results might seem surprising, since degradation reactions take place during immersion. In fact, an increase in the hardness of PLA after exposure to ethanolic food simulants has been already reported [32]. Indeed, hardness is not only affected by molecular weight, but also by other factors such as molecular configuration and crystallinity degree [62]. In the case of the sample immersed in simulant A, an increase of around 7\% $(p<0.05)$ in the Vickers hardness was observed, although no important crystallization was determined by means of DSC or ATR-FTIR spectroscopy. This behavior suggests that physical aging, which was observed by means of DSC, is the main reason for the increase in the hardness of the immersed samples. Authors such as Wang and Mano [63], 
Pan et al. [64], and Cui et al. [49] have pointed out that physical aging, in dry conditions, of PLA leads to an increase in the hardness and stiffness of the polymer. Figure 8 also shows that the samples immersed in the simulant D1 presented a larger increase in the Vickers hardness $(p<0.05)$, which can be attributed to the important increase in the crystallinity degree upon immersion, as was observed by means of DSC and ATR-FTIR spectroscopy.

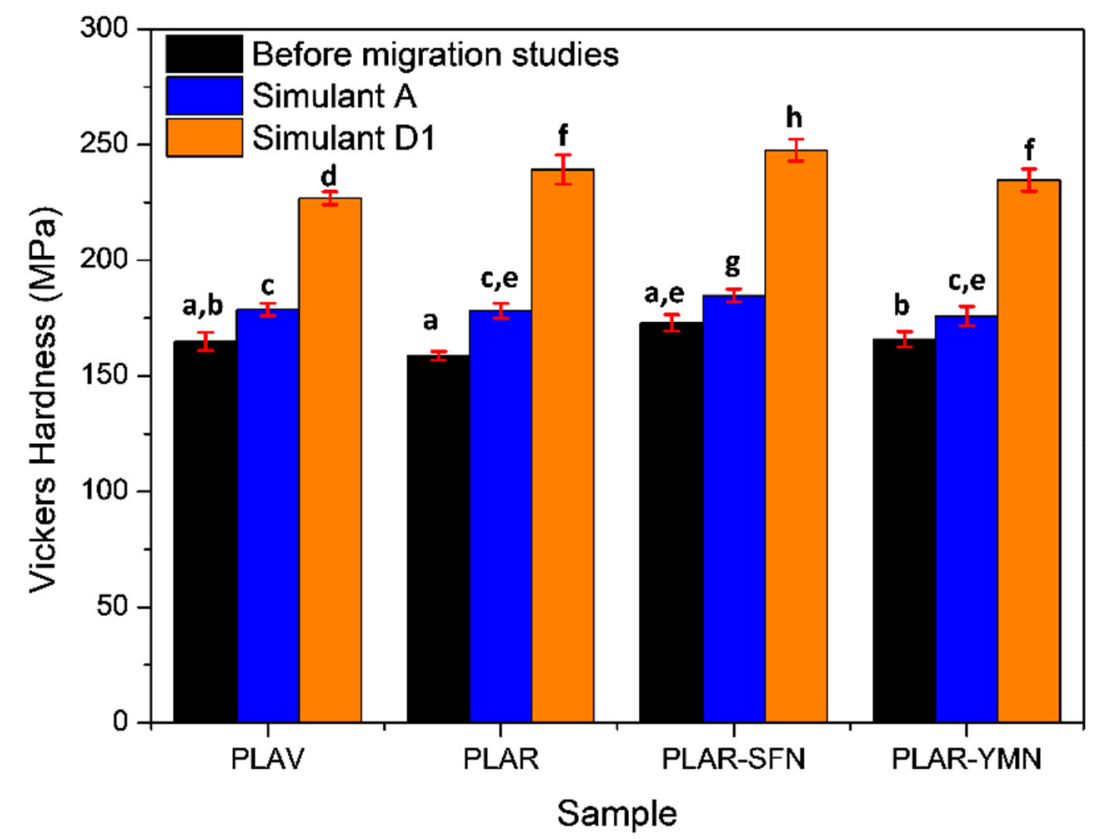

Figure 8. Vickers hardness of the samples before and after immersion in food simulants. ${ }^{\mathrm{a}-\mathrm{h}}$ Different letters indicate statistically significant differences between formulations $(p<0.05)$.

\subsection{Disintegration under Industrial Composting Conditions}

As PLA cannot be infinitely recycled, due to each reprocessing cycle negatively affecting the thermomechanical properties of the PLA matrix $[65,66]$, the recycled PLA-based materials after their useful life can be composted under industrial composting conditions in the same way as single-use PLA-based materials [67]. The degree of physical disintegration as a function of time was quantitatively monitored by the determination of samples' mass loss, as is shown in Figure 9. Meanwhile, photographs were taken to qualitatively check the visual appearance of the recovered films at different composting times (Figure 10). A reduction in the molecular weight of the films during composting was followed by a reduction in the intrinsic viscosity (Table 4). The structural and chemical changes were followed by means of DSC (Figure 11) and ATR-FTIR (Figure 12).

Figure 10 shows that, after 4 days of composting disintegration, all the samples increased their opacity. However, no significant changes were observed in the mass loss among film formulations after 4 days of composting disintegration. The disintegrability of PLA under composting conditions starts by a hydrolysis process and it is further followed by enzymatic actions of microorganisms [8,41]. The increased opacity of PLA indicates that the hydrolytic disintegration process has started, since the water absorption and the presence of products generated during the hydrolytic degradation produce changes in the refraction index of polymeric materials [68]. Although no significant mass losses were observed, the PLAV and PLAR samples exhibited a reduction in the molecular weight after 4 days, as can be seen from the intrinsic viscosity reduction of about $42 \%$ (Table 4). A smaller reduction in the molecular weight was observed in the nanocomposites (around 33\%). This result suggests that nanoparticles protect the polymeric matrix from the degradation process, due to the above-described barrier effect, which restricts the water penetration and delays the disintegration process. A similar behavior has already been observed in previous works, and it has been ascribed to the nucleating effect of such 
nanoparticles on PLA matrix [26]. In fact, TGA results show that the reduction in $\mathrm{T}_{10}$ values after 4 days in composting was around $45^{\circ} \mathrm{C}$ in neat PLA, between $27^{\circ} \mathrm{C}$ and $29^{\circ} \mathrm{C}$ in PLAR and PLAR-SFNs, and around $15^{\circ} \mathrm{C}$ for PLAR-YMNs. This lesser reduction in the $\mathrm{T}_{10}$ values may be related to the antioxidant effect of $\mathrm{YMNs}$ provided by the high amount of total polyphenol content (TPC of YMNs $=41 \pm 1 \mathrm{mg}$ of gallic acid/g yerba mate nanoparticles [26]), making YMNs able to protect the polymeric matrix from thermal degradation. The large decrease in the thermal stability after only 4 days of degradation was probably due to the loss of low-molecular-mass compounds, which were generated by hydrolysis during the initial degradation stage.

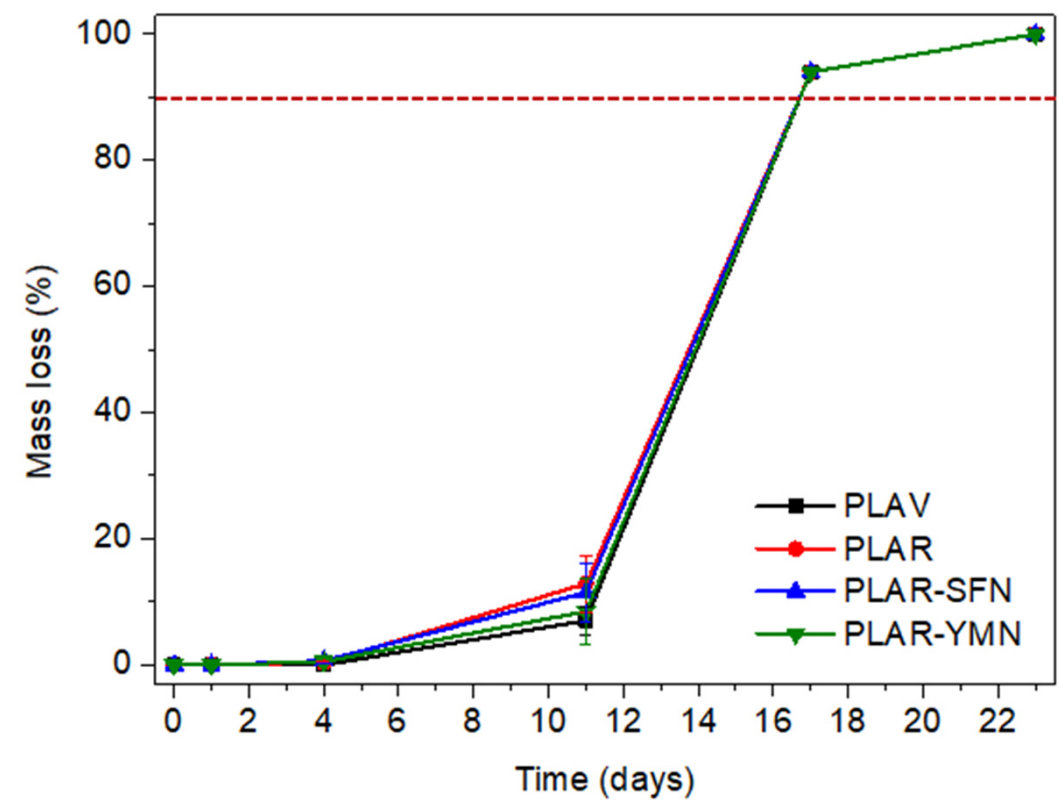

Figure 9. Degree of disintegration of films under composting conditions as a function of time.

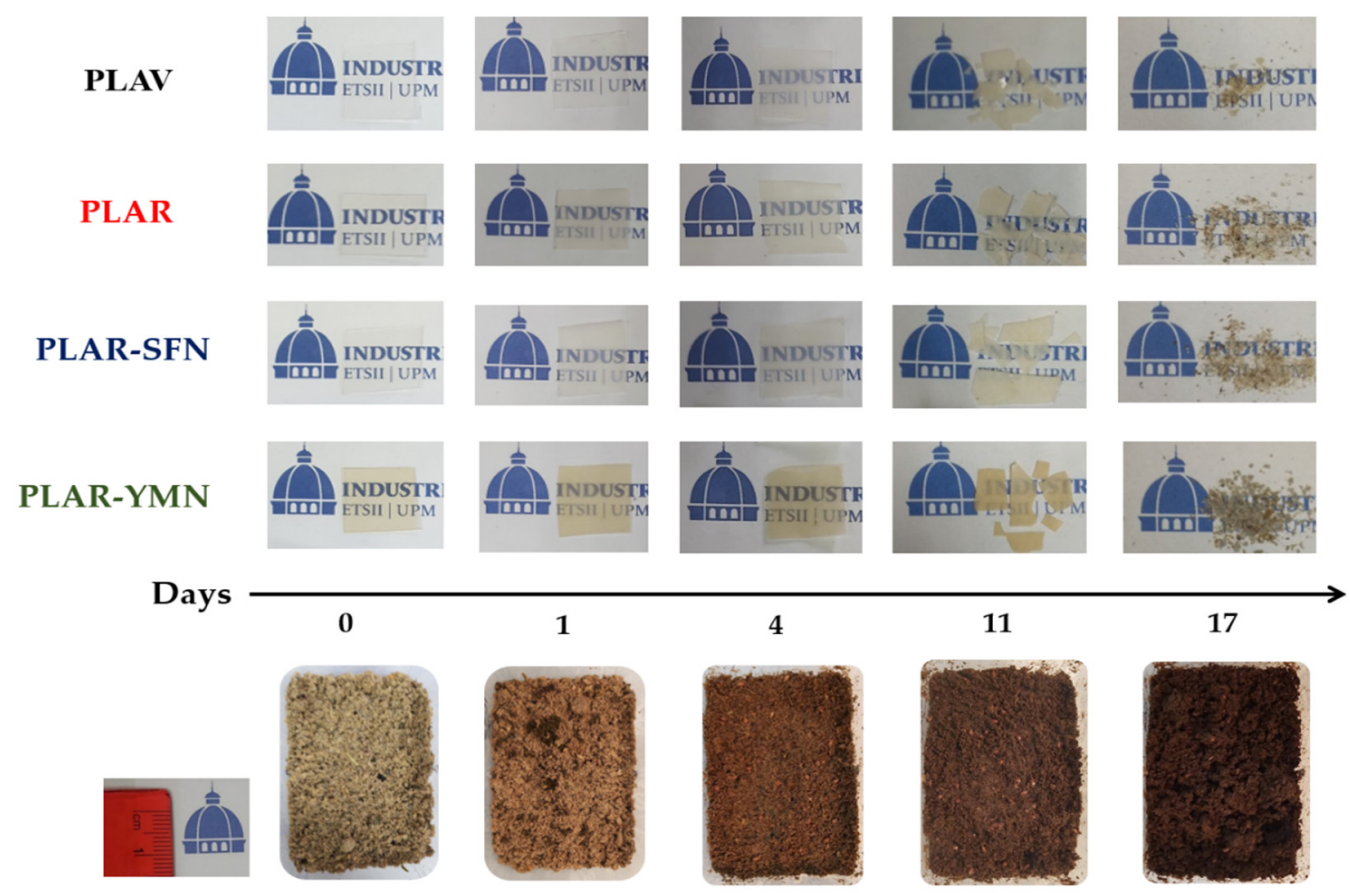

Figure 10. Visual appearance of the films and the compost medium during the composting test. 
Table 4. Intrinsic viscosity and TGA parameters of the samples during disintegration under composting conditions.

\begin{tabular}{ccccc}
\hline Sample & $\begin{array}{c}\text { Disintegration Time } \\
\text { (Day) }\end{array}$ & $\begin{array}{c}\text { Intrinsic Viscosity } \\
(\mathbf{m L} / \mathbf{g})\end{array}$ & $\begin{array}{c}\mathbf{T}_{\mathbf{1 0}} \\
\left({ }^{\circ} \mathbf{C}\right)\end{array}$ & $\begin{array}{c}\mathbf{T}_{\max } \\
\left({ }^{\circ} \mathbf{C}\right)\end{array}$ \\
\hline \multirow{3}{*}{ PLAV } & 0 & $159 \pm 1$ & 328.2 & 354.5 \\
& 4 & $93 \pm 2$ & 282.5 & 319.3 \\
\multirow{2}{*}{ PLAR } & 11 & $24 \pm 1$ & 266.1 & 339.2 \\
\hline \multirow{2}{*}{ PLAR-SFNs } & 0 & $135 \pm 1$ & 323.1 & 359.5 \\
& 4 & $77 \pm 1$ & 295.5 & 333.6 \\
& 11 & $17 \pm 1$ & 263.1 & 340.5 \\
\hline \multirow{2}{*}{ PLAR-YMNs } & 0 & $119 \pm 2$ & 331.2 & 369.1 \\
& 4 & $79 \pm 3$ & 312.0 & 344.1 \\
& 11 & $27 \pm 1$ & 301.7 & 336.9 \\
\hline
\end{tabular}
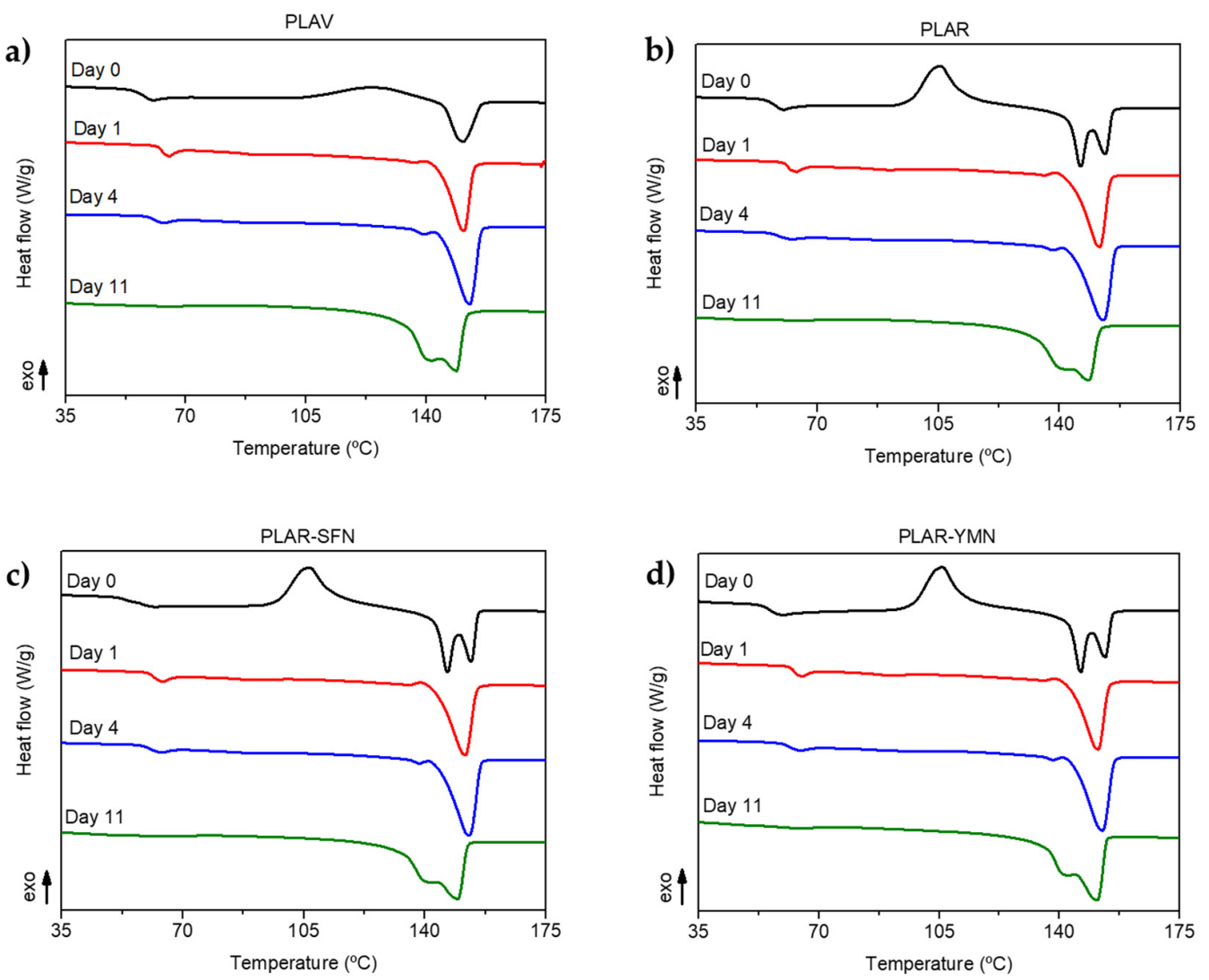

Figure 11. DSC first heating scan of (a) virgin PLA (PLAV), (b) recycled PLA (PLAR), (c) recycled PLA-silk fibroin nanoparticles nanocomposite PLAR-SFN, and (d) recycled PLA-yerba mate nanoparticles nanocomposite PLAR-YMN before and after different days of disintegration under composting conditions. 

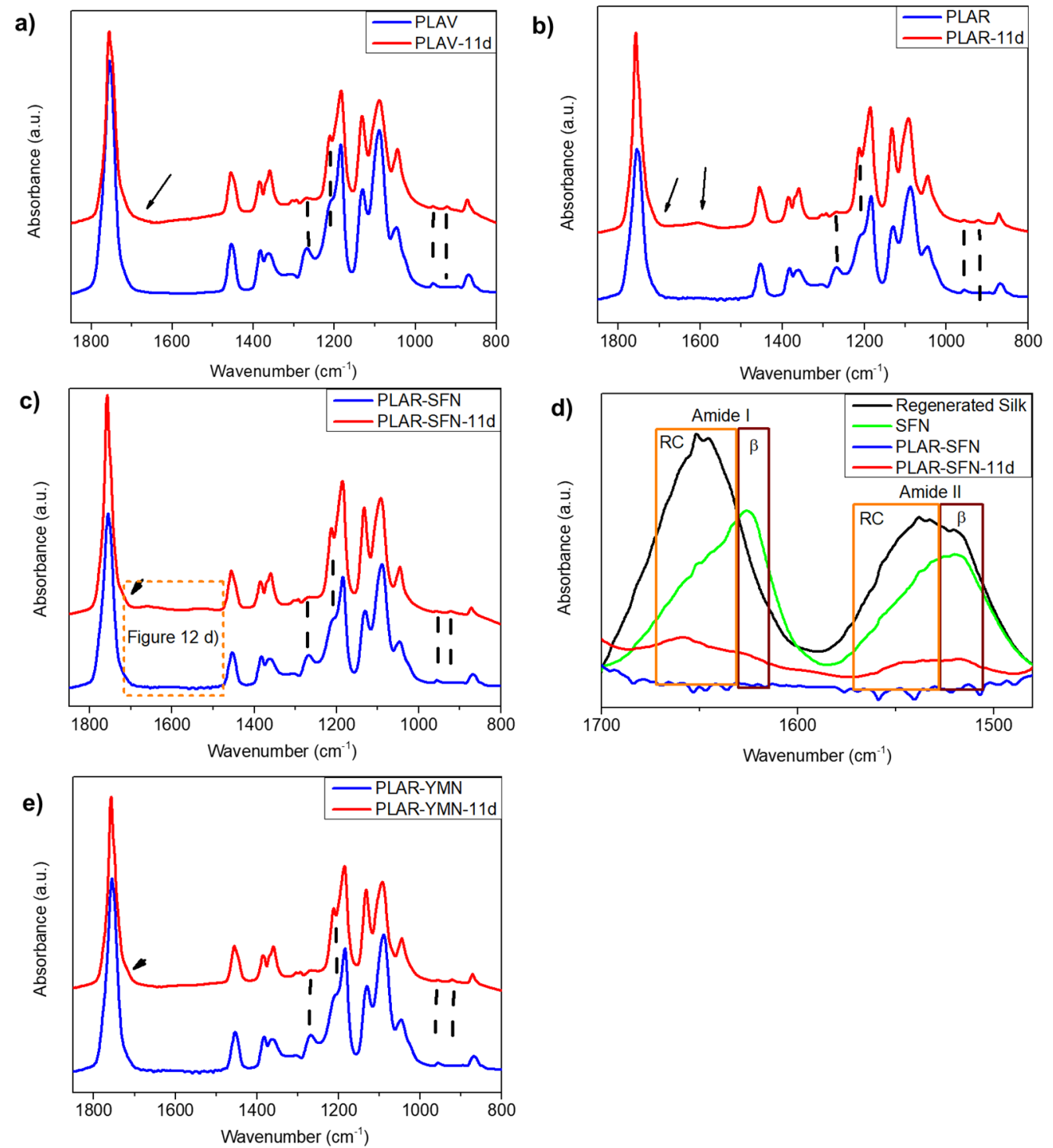

Figure 12. ATR-FTIR spectra of (a) PLA, (b) PLAR, (c) PLAR-SFNs, (d) the amide region of the PLAR-SFNs (spectra of regenerated silk, black, and SFNs, green, were added for reference), and (e) PLAR-YMNs before and after 11 days of disintegration under composting conditions.

Figure 11 shows that after only one day in compost all the formulations crystallized, as the endotherm of the cold crystallization disappeared. After 11 days of composting, the glass transition peak disappeared, which could be attributed to the degradation of the amorphous zones in PLA. This would be in good agreement with the severe disintegration observed in Figure 10, and the large reduction in the intrinsic viscosity shown in Table 4. Furthermore, an additional melting event at a lower temperature than the melting point of PLA before composting was observed as a shoulder, which could be ascribed to the presence of shorter polymer chains due to the degradation of the PLA matrix [69].

The chemical and structural changes in the materials before and after 11 days of composting were also followed by ATR-FTIR. The spectra of analyzed materials after 11 days under composting conditions (Figure 12) showed important differences with respect to those of the starting materials. On the one hand, in the spectrum region between 1750 and $1500 \mathrm{~cm}^{-1}$, all the materials subjected to composting conditions for 11 days showed a shoulder around $1700 \mathrm{~cm}^{-1}$, assigned to the formation of -COOH groups during hydrolytic degradation [70]. Moreover, a small but broad band centered at $1600 \mathrm{~cm}^{-1}$ appeared in PLAR, which is related to the presence of carboxylate ions in degraded PLA formulations $[69,71]$. It is also worth noting that, in the PLAR-SFNs nanocomposite, the 
analysis of the Amide I and II regions of the ATR-FTIR spectra of silk fibroin materials can be used as the most informative for their secondary structure determination $[35,72,73]$. Figure $12 \mathrm{~d}$ shows that, although at day 0 both bands were hindered by the PLAR spectrum due their low SFN/PLAR ratio, a remarkable increase in the signals of these SFNs bands is appreciated after 11 days. The spectra of silk fibroin nanoparticles, mainly in a $\beta$-sheet, highly crystalline conformation (amide I at $\sim 1626 \mathrm{~cm}^{-1}$ and amide II at $\sim 1520 \mathrm{~cm}^{-1}$ ), and the regenerated silk fibroin (non-crystalline or Silk I), which was mainly in a random coil (RC) conformation (amide I at $\sim 1650 \mathrm{~cm}^{-1}$ and amide II at $\sim 1538 \mathrm{~cm}^{-1}$ ), are presented in the figure as a reference. In both cases, the signals are composed by the sum of the contributions of the random coil and $\beta$-sheet conformations. This behavior could be explained by the fact that the decomposition of the PLAR makes accessible the crystallized silk fibroin (highly ordered, insoluble, and stable) present in the nanoparticles to the ATR, arising from the background of the PLAR spectrum. However, the SFNs have been partially decomposed during this period into soluble peptides, mainly in a "random coil" conformation, which are visible too [74]. Finally, it should be noted that the spectrum of the PLAR-YMNs nanocomposite was the most similar to that of virgin material in good agreement with the lower disintegration rate of this formulation at this stage due to the protective effect of YMNs.

On the other hand, all composted materials after 11 days showed an increase in the intensity of the absorption bands at 1211 and $920 \mathrm{~cm}^{-1}$, along with a decrease in the intensity of the absorption band at $1265 \mathrm{~cm}^{-1}$ and $956 \mathrm{~cm}^{-1}$. The bands at $1211 \mathrm{~cm}^{-1}$ $\left(v_{\mathrm{as}}(\mathrm{C}-\mathrm{CO}-\mathrm{O})+\mathrm{r}_{\mathrm{as}}\left(\mathrm{CH}_{3}\right)\right)$ and $920 \mathrm{~cm}^{-1}$ (assigned above) have been associated in the literature with the formation of crystalline polymorphs, while the bands at $1265 \mathrm{~cm}^{-1}$ $\left((v(\mathrm{C}-\mathrm{H})+v(\mathrm{C}-\mathrm{CO}-\mathrm{O}))\right.$ and at $956 \mathrm{~cm}^{-1}$ correspond to the amorphous phase [53]. The observed results suggest that the amorphous phase considerably decreased due to the earlier disintegration of the amorphous regions, while the crystalline regions remained in the polymer matrix as was already pointed out for DSC results [71].

After 17 days under composting conditions, tiny pieces of polymeric samples were recovered (Figure 10) and all the formulations had lost more than $90 \%$ of their initial mass, which is frequently used as the goal of the disintegrability test [68,71]. After 23 days, the materials had completely disappeared, and the compost soil showed a $\mathrm{pH}$ around 7. Moreover, the compost soil's color changed during the composting test, as is shown at the bottom of Figure 10, resulting in a dark humus soil as a consequence of the aerobic fermentation, confirming the success of the composting test.

\section{Conclusions}

Nanocomposites based on recycled PLA reinforced with 1 wt.\% of silk fibroin or yerba mate nanoparticles were developed and exposed to two ethanolic food simulants containing $10 \% v / v$ of ethanol (simulant A) and $50 \% v / v$ of ethanol (simulant D1). The migration levels of the nanocomposites were below the overall migration limits established in the current legislation, suggesting that these recycled films can be used as food packaging materials. The effects of ethanol on the structural, thermal, and mechanical properties of the developed materials after the overall migration tests were studied. After the immersion in food simulants, the materials showed an increase in the Vickers hardness that was more marked in the simulant D1, directly related to the larger increase in the crystallinity degree in this food simulant as was observed by DSC and ATR-FTIR spectroscopy. Finally, the materials were subjected to simulated composting conditions, and they were successfully disintegrated in less than one month, underlining their biodegradable character. The ability of both nanoparticles to act as reinforcing fillers for recycled PLA slowed down its disintegration rate under composting conditions due to the smaller reduction in the molecular weight of the polymeric matrix, as revealed by the intrinsic viscosity and ATRFTIR measurements. 
The obtained results suggest that recycled PLA performance can be improved by the addition of $1 \mathrm{wt}$ \% of either SFNs or YMNs, while the obtained nanocomposites are promising materials for sustainable food packaging applications.

Supplementary Materials: The following are available online at https: / www.mdpi.com/article/ 10.3390/polym13121925/s1, Figure S1: (a) DLS measurements of YMNs solution and powder and (b) TEM image of YMNs powder; Figure S2: (a) DLS measurements of SFNs and (b) TEM image of SFNs powder and Figure S3: FE-SEM images of: PLAV (a), PLAR (b), and nanocomposites: PLAR loaded with $1 \%$ wt. of YMN (c) and PLAR loaded with $2 \%$ wt. of SFN (d).

Author Contributions: Conceptualization, J.M.U., J.L.C., M.U.d.l.O., M.P.A. and F.R.B.; methodology, J.M.U., A.A.L.-P., M.P.A. and M.U.d.1.O.; investigation, F.R.B., G.G., D.E.A., A.A.L.-P. and M.P.A.; writing-original draft preparation, F.R.B., M.P.A., M.U.d.1.O. and A.A.L.-P.; writing-review and editing, A.A.L.-P. and J.M.U.; supervision, M.P.A., J.L.C., J.M.U. and M.U.d.l.O.; project administration, J.L.C. and J.M.U.; funding acquisition J.M.U., J.L.C. and A.A.L.-P. All authors have read and agreed to the published version of the manuscript.

Funding: This research was funded by the European Union's Horizon 2020 research and innovation program under grant agreement No. 860407 BIO-PLASTICS EUROPE, by MINECO-Spain under project CTM2017-88989-P, as well as Universidad Politécnica de Madrid under project UPM RP 160543006 and the European Commission ERDF/FEDER Operational Programme 'Murcia' CCI No 2007ES161PO001 (Project No. 14-20/20). A.A.L.-P's research contract was partially funded (80\%) by the ERDF/FEDER Operational Programme 'Murcia' CCI No 2007ES161PO001 (Project No. 14-20/20).

Institutional Review Board Statement: Not applicable.

Informed Consent Statement: Not applicable.

Data Availability Statement: Research data are available from the public repository e-cienciadatos https: / / doi.org/10.21950/QOTKHI (accessed on 7 June 2021).

Conflicts of Interest: The authors declare no conflict of interest.

\section{References}

1. Reddy, M.M.; Vivekanandhan, S.; Misra, M.; Bhatia, S.K.; Mohanty, A.K. Biobased Plastics and Bionanocomposites: Current Status and Future Opportunities. Prog. Polym. Sci. 2013, 38, 1653-1689. [CrossRef]

2. Farah, S.; Anderson, D.G.; Langer, R. Physical and Mechanical Properties of PLA, and their Functions in Widespread ApplicationsA Comprehensive Review. Adv. Drug Deliv. Rev. 2016, 107, 367-392. [CrossRef] [PubMed]

3. Raquez, J.; Habibi, Y.; Murariu, M.; Dubois, P. Polylactide (PLA)-Based Nanocomposites. Prog. Polym. Sci. 2013, 38, 1504-1542. [CrossRef]

4. Castro-Aguirre, E.; Iñiguez-Franco, F.; Samsudin, H.; Fang, X.; Auras, R. Poly(Lactic Acid)—Mass Production, Processing, Industrial Applications, and End of Life. Adv. Drug Deliv. Rev. 2016, 107, 333-366. [CrossRef]

5. Arrieta, P.M.; Samper, D.M.; Aldas, M.; López, J. On the use of PLA-PHB Blends for Sustainable Food Packaging Applications. Materials 2017, 10, 1008. [CrossRef] [PubMed]

6. Luzi, F.; Torre, L.; Kenny, J.M.; Puglia, D. Bio- and Fossil-Based Polymeric Blends and Nanocomposites for Packaging: StructureProperty Relationship. Materials 2019, 12, 471. [CrossRef] [PubMed]

7. IfBB-Institute for Bioplastics and Biocomposites. Biopolymers Facts and Statistics 2020; Hochschule Hannover University of Applied Sciences and Arts: Hannover, Germany, 2020.

8. Kale, G.; Auras, R.; Singh, S.P. Comparison of the Degradability of Poly(Lactide) Packages in Composting and Ambient Exposure Conditions. Packag. Technol. Sci. 2007, 20, 49-70. [CrossRef]

9. Arrieta, M.P. Influence of Plasticizers on the Compostability of Polylactic Acid. J. Appl. Res. Technol. Eng. 2021, 2, 1-9. [CrossRef]

10. Haider, T.; Völker, C.; Kramm, J.; Landfester, K.; Wurm, F.R. Plastics of the Future? the Impact of Biodegradable Polymers on the Environment and on Society. Angew. Chem. Int. Ed. 2019, 58, 50-62. [CrossRef]

11. Niaounakis, M. Recycling of Biopolymers-The Patent Perspective. Eur. Polym. J. 2019, 114, 464-475. [CrossRef]

12. Briassoulis, D.; Pikasi, A.; Hiskakis, M. Recirculation Potential of Post-Consumer/Industrial Bio-Based Plastics through Mechanical Recycling-Techno-Economic Sustainability Criteria and Indicators. Polym. Degrad. Stab. 2020, 109217. [CrossRef]

13. European Comission. A European Strategy for Plastics in a Circular Economy; European Comission: Brussels, Belgium, 2018.

14. De Andrade, M.F.; Souza, P.M.; Cavalett, O.; Morales, A.R. Life Cycle Assessment of Poly(Lactic Acid) (PLA): Comparison between Chemical Recycling, Mechanical Recycling and Composting. J. Polym. Environ. 2016, 24, 372-384. [CrossRef]

15. Maga, D.; Hiebel, M.; Thonemann, N. Life Cycle Assessment of Recycling Options for Polylactic Acid. Resour. Conserv. Recycl. 2019, 149, 86-96. [CrossRef] 
16. Samper, M.D.; Bertomeu, D.; Arrieta, M.P.; Ferri, J.M.; López-Martínez, J. Interference of Biodegradable Plastics in the Polypropylene Recycling Process. Materials 2018, 11, 1886. [CrossRef] [PubMed]

17. McLauchlin, A.R.; Ghita, O.; Gahkani, A. Quantification of PLA Contamination in PET during Injection Moulding by in-Line NIR Spectroscopy. Polym. Test. 2014, 38, 46-52. [CrossRef]

18. Beltrán, F.R.; Lorenzo, V.; Acosta, J.; de la Orden, M.U.; Urreaga, J.M. Effect of Simulated Mechanical Recycling Processes on the Structure and Properties of Poly(Lactic Acid). J. Environ. Manag. 2018, 216, 25-31. [CrossRef] [PubMed]

19. Beltrán, F.R.; Infante, C.; de la Orden, M.U.; Urreaga, J.M. Mechanical Recycling of Poly(Lactic Acid): Evaluation of a Chain Extender and a Peroxide as Additives for Upgrading the Recycled Plastic. J. Clean. Prod. 2019, 219, 46-56. [CrossRef]

20. Tuna, B.; Ozkoc, G. Effects of Diisocyanate and Polymeric Epoxidized Chain Extenders on the Properties of Recycled Poly(Lactic Acid). J. Polym. Environ. 2017, 25, 983-993. [CrossRef]

21. Beltrán, F.R.; Climent-Pascual, E.; de la Orden, M.U.; Urreaga, J.M. Effect of Solid-State Polymerization on the Structure and Properties of Mechanically Recycled Poly(Lactic Acid). Polym. Degrad. Stab. 2020, 171, 109045. [CrossRef]

22. Beltrán, F.R.; de la Orden, M.U.; Urreaga, J.M. Amino-Modified Halloysite Nanotubes to Reduce Polymer Degradation and Improve the Performance of Mechanically Recycled Poly(Lactic Acid). J. Polym. Environ. 2018, 26, 4046-4055. [CrossRef]

23. Beltrán, F.R.; Arrieta, M.P.; Gaspar, G.; de la Orden, M.U.; Urreaga, J.M. Effect of Iignocellulosic Nanoparticles Extracted from Yerba Mate (Ilex paraguariensis) on the Structural, Thermal, Optical and Barrier Properties of Mechanically Recycled Poly(Lactic Acid). Polymers 2020, 12, 1690. [CrossRef]

24. Beltrán, F.R.; Gaspar, G.; Chomachayi, M.D.; Jalali-Arani, A.; Lozano-Pérez, A.A.; Cenis, J.L.; María, U.; Pérez, E.; Urreaga, J.M. Influence of Addition of Organic Fillers on the Properties of Mechanically Recycled PLA. Environ. Sci. Pollut. Res. 2020, 28, 24291-24304. [CrossRef]

25. Villegas, C.; Arrieta, M.P.; Rojas, A.; Torres, A.; Faba, S.; Toledo, M.J.; Gutierrez, M.A.; Zavalla, E.; Romero, J.; Galotto, M.J.; et al. PLA/Organoclay Bionanocomposites Impregnated with Thymol and Cinnamaldehyde by Supercritical Impregnation for Active and Sustainable Food Packaging. Compos. Part B Eng. 2019, 176, 107336. [CrossRef]

26. Arrieta, M.P.; Peponi, L.; López, D.; Fernández-García, M. Recovery of Yerba Mate (Ilex paraguariensis) Residue for the Development of PLA-Based Bionanocomposite Films. Ind. Crops Prod. 2018, 111, 317-328. [CrossRef]

27. Deladino, L.; Anbinder, P.S.; Navarro, A.S.; Martino, M.N. Encapsulation of Natural Antioxidants Extracted from Ilex paraguariensis. Carbohydr. Polym. 2008, 71, 126-134. [CrossRef]

28. De Mejía, E.G.; Song, Y.S.; Heck, C.I.; Ramírez-Mares, M. Yerba Mate Tea (Ilex paraguariensis): Phenolics, Antioxidant Capacity and in Vitro Inhibition of Colon Cancer Cell Proliferation. J. Funct. Foods 2010, 2, 23-34. [CrossRef]

29. Chomachayi, M.D.; Jalali-arani, A.; Beltrán, F.R.; de la Orden, M.U.; Urreaga, J.M. Biodegradable Nanocomposites Developed from PLA/PCL Blends and Silk Fibroin Nanoparticles: Study on the Microstructure, Thermal Behavior, Crystallinity and Performance. J. Polym. Environ. 2020, 28, 1252-1264. [CrossRef]

30. Gong, Y.; Li, L.; Gong, D.; Yin, H.; Zhang, J. Biomolecular Evidence of Silk from 8500 Years Ago. PLoS ONE 2016, 11, e0168042.

31. Huang, W.; Ling, S.; Li, C.; Omenetto, F.G.; Kaplan, D.L. Silkworm Silk-Based Materials and Devices Generated using BioNanotechnology. Chem. Soc. Rev. 2018, 47, 6486-6504. [CrossRef] [PubMed]

32. Arrieta, M.P.; Castro-Lopez, M.D.; Rayón, E.; Barral-Losada, L.F.; López-Vilariño, J.M.; López, J.; González-Rodríguez, M.V. Plasticized Poly(Lactic Acid)-Poly(Hydroxybutyrate) (PLA-PHB) Blends Incorporated with Catechin Intended for Active Food-Packaging Applications. J. Agric. Food Chem. 2014, 62, 10170-10180. [CrossRef]

33. Arrieta, M.P.; de Dicastillo, C.L.; Garrido, L.; Roa, K.; Galotto, M.J. Electrospun PVA Fibers Loaded with Antioxidant Fillers Extracted from Durvillaea Antarctica Algae and their Effect on Plasticized PLA Bionanocomposites. Eur. Polym. J. 2018, 103, 145-157. [CrossRef]

34. Lozano-Pérez, A.A.; Rivero, H.C.; Hernández, M.D.; Pagán, A.; Montalbán, M.G.; Víllora, G.; Cénis, J.L. Silk Fibroin Nanoparticles: Efficient Vehicles for the Natural Antioxidant Quercetin. Int. J. Pharm. 2017, 518, 11-19. [CrossRef] [PubMed]

35. Carissimi, G.; Lozano-Pérez, A.A.; Montalbán, M.G.; Aznar-Cervantes, S.; Cenis, J.L.; Víllora, G. Revealing the Influence of the Degumming Process in the Properties of Silk Fibroin Nanoparticles. Polymers 2019, 11, 2045. [CrossRef] [PubMed]

36. Ajisawa, A. Dissolution of Silk Fibroin with Calciumchloride/Ethanol Aqueous Solution; Studies on the Dissolution of Silk Fibroin. (IX). J. Sericult. Sci. Jpn. 1998, 67, 91-94.

37. Chariyachotilert, C.; Joshi, S.; Selke, S.E.M.; Auras, R. Assessment of the Properties of Poly(L-Lactic Acid) Sheets Produced with Differing Amounts of Postconsumer Recycled Poly(L-Lactic Acid). J. Plast. Film Sheeting 2012, 28, 314-335. [CrossRef]

38. European Comission. Commission Regulation (EU) No 10/2011 of 14 January 2011 on Plastic Materials and Articles Intended to Come into Contact with Food; European Comission: Brussels, Belgium, 2011.

39. International Organization for Standarization. ISO 1186-1 Materials and Articles in Contact with Foodstuffs. Plastics. Part 1: Guide to the Selection of Conditions and Test Methods for Overall Migration; International Organization for Standarization: Geneve, Switzerland, 2002.

40. International Organization for Standarization. ISO 20200: Determination of the Degree of Disintegration of Plastic Materials under Simulated Composting Conditions in a Laboratory-Scale Test; International Organization for Standarization: Geneve, Switzerland, 2016.

41. Arrieta, M.P.; Rivera, K.A.; Salgado, C.; Richa, A.M.; López, D.; Peponi, L. Degradation Under Composting Conditions of Lysine-Modified Polyurethane Based on PCL obtained by Lipase Biocatalysis. Polym. Degrad. Stab. 2018, 152, 139-146. [CrossRef] 
42. Meaurio, E.; López-Rodríguez, N.; Sarasua, J.R. Infrared Spectrum of Poly(L-Lactide): Application to Crystallinity Studies. Macromolecules 2006, 39, 9291-9301. [CrossRef]

43. Fortunati, E.; Peltzer, M.; Armentano, I.; Torre, L.; Jiménez, A.; Kenny, J.M. Effects of Modified Cellulose Nanocrystals on the Barrier and Migration Properties of PLA Nano-Biocomposites. Carbohydr. Polym. 2012, 90, 948-956. [CrossRef]

44. Iñiguez-Franco, F.; Auras, R.; Burgess, G.; Holmes, D.; Fang, X.; Rubino, M.; Soto-Valdez, H. Concurrent Solvent Induced Crystallization and Hydrolytic Degradation of PLA by Water-Ethanol Solutions. Polymer 2016, 99, 315-323. [CrossRef]

45. Sonchaeng, U.; Iñiguez-Franco, F.; Auras, R.; Selke, S.; Rubino, M.; Lim, L. Poly(Lactic Acid) Mass Transfer Properties. Prog. Polym. Sci. 2018, 86, 85-121. [CrossRef]

46. Iñiguez-Franco, F.; Auras, R.; Rubino, M.; Dolan, K.; Soto-Valdez, H.; Selke, S. Effect of Nanoparticles on the Hydrolytic Degradation of PLA-Nanocomposites by Water-Ethanol Solutions. Polym. Degrad. Stab. 2017, 146, 287-297. [CrossRef]

47. Brüster, B.; Addiego, F.; Hassouna, F.; Ruch, D.; Raquez, J.M.; Dubois, P. Thermo-Mechanical Degradation of Plasticized Poly(Lactide) After Multiple Reprocessing to Simulate Recycling: Multi-Scale Analysis and Underlying Mechanisms. Polym. Degrad. Stab. 2016, 131, 132-144. [CrossRef]

48. Di Lorenzo, M.L. Calorimetric Analysis of the Multiple Melting Behavior of Poly(L-Lactic Acid). J. Appl. Polym. Sci. 2006, 100, 3145-3151. [CrossRef]

49. Cui, L.; Imre, B.; Tátraaljai, D.; Pukánszky, B. Physical Ageing of Poly(Lactic Acid): Factors and Consequences for Practice. Polymer 2020, 186, 122014. [CrossRef]

50. Celli, A.; Scandola, M. Thermal Properties and Physical Ageing of Poly (L-Lactic Acid). Polymer 1992, 33, 2699-2703. [CrossRef]

51. Righetti, M.C.; Gazzano, M.; Delpouve, N.; Saiter, A. Contribution of the Rigid Amorphous Fraction to Physical Ageing of Semi-Crystalline PLLA. Polymer 2017, 125, 241-253. [CrossRef]

52. Vyavahare, O.; Ng, D.; Hsu, S.L. Analysis of Structural Rearrangements of Poly(Lactic Acid) in the Presence of Water. J. Phys. Chem. B 2014, 118, 4185-4193. [CrossRef]

53. Beltrán, F.R.; de la Orden, M.U.; Lorenzo, V.; Pérez, E.; Cerrada, M.L.; Martínez Urreaga, J. Water-Induced Structural Changes in Poly(Lactic Acid) and PLLA-Clay Nanocomposites. Polymer 2016, 107, 211-222. [CrossRef]

54. Badia, J.D.; Santonja-Blasco, L.; Martínez-Felipe, A.; Ribes-Greus, A. Hygrothermal Ageing of Reprocessed Polylactide. Polym. Degrad. Stab. 2012, 97, 1881-1890. [CrossRef]

55. Simmons, H.; Kontopoulou, M. Hydrolytic Degradation of Branched PLA Produced by Reactive Extrusion. Polym. Degrad. Stab. 2018, 158, 228-237. [CrossRef]

56. Kister, G.; Cassanas, G.; Vert, M. Effects of Morphology, Conformation and Configuration on the IR and Raman Spectra of various Poly(Lactic Acid)S. Polymer 1998, 39, 267-273. [CrossRef]

57. Chen, X.; Han, L.; Zhang, T.; Zhang, J. Influence of Crystal Polymorphism on Crystallinity Calculation of Poly(L-Lactic Acid) by Infrared Spectroscopy. Vib. Spectrosc. 2014, 70, 1-5. [CrossRef]

58. Fukushima, K.; Tabuani, D.; Dottori, M.; Armentano, I.; Kenny, J.M.; Camino, G. Effect of Temperature and Nanoparticle Type on Hydrolytic Degradation of Poly(Lactic Acid) Nanocomposites. Polym. Degrad. Stab. 2011, 96, 2120-2129. [CrossRef]

59. Beltrán, F.R.; Lorenzo, V.; de la Orden, M.U.; Martínez-Urreaga, J. Effect of Different Mechanical Recycling Processes on the Hydrolytic Degradation of Poly(L-Lactic Acid). Polym. Degrad. Stab. 2016, 133, 339-348. [CrossRef]

60. Fenoglio, D.; Madrid, D.S.; Moyano, J.A.; Ferrario, M.; Guerrero, S.; Matiacevich, S. Active Food Additive Based on Encapsulated Yerba Mate (Ilex paraguariensis) Extract: Effect of Drying Methods on the Oxidative Stability of a Real Food Matrix (Mayonnaise). J. Food Sci. Technol. 2021, 58, 1574-1584. [CrossRef] [PubMed]

61. Pillin, I.; Montrelay, N.; Bourmaud, A.; Grohens, Y. Effect of Thermo-Mechanical Cycles on the Physico-Chemical Properties of Poly(Lactic Acid). Polym. Degrad. Stab. 2008, 93, 321-328. [CrossRef]

62. Perego, G.; Cella, G.D.; Bastioli, C. Effect of Molecular Weight and Crystallinity on Poly(Lactic Acid) Mechanical Properties. J. Appl. Polym. Sci. 1996, 59, 37-43. [CrossRef]

63. Wang, Y.; Mano, J.F. Effect of Structural Relaxation at Physiological Temperature on the Mechanical Property of Poly(L-Lactic Acid) Studied by Microhardness Measurements. J. Appl. Polym. Sci. 2006, 100, 2628-2633. [CrossRef]

64. Pan, P.; Zhu, B.; Inoue, Y. Enthalpy Relaxation and Embrittlement of Poly(L-Lactide) during Physical Aging. Macromolecules 2007, 40, 9664-9671. [CrossRef]

65. Badia, J.D.; Ribes-Greus, A. Mechanical Recycling of Polylactide, Upgrading Trends and Combination of Valorization Techniques. Eur. Polym. J. 2016, 84, 22-39. [CrossRef]

66. Agüero, A.; Morcillo, D.M.; Quiles-Carrillo, L.; Balart, R.; Boronat, T.; Lascano, D.; Torres-Giner, S.; Fenollar, O. Study of the Influence of the Reprocessing Cycles on the Final Properties of Polylactide Pieces obtained by Injection Molding. Polymers 2019, 11, 1908. [CrossRef]

67. Beltrán, F.R.; Arrieta, M.P.; Moreno, E.; Gaspar, G.; Muneta, L.M.; Carrasco-Gallego, R.; Yáñez, S.; Hidalgo-Carvajal, D.; de la Orden, M.U.; Martínez Urreaga, J. Evaluation of the Technical Viability of Distributed Mechanical Recycling of PLA 3D Printing Wastes. Polymers 2021, 13, 1247. [CrossRef]

68. Fortunati, E.; Puglia, D.; Santulli, C.; Sarasini, F.; Kenny, J.M. Biodegradation of Phormium Tenax/Poly(Lactic Acid) Composites. J. Appl. Polym. Sci. 2012, 125, E562-E572. [CrossRef] 
69. Fortunati, E.; Armentano, I.; Iannoni, A.; Barbale, M.; Zaccheo, S.; Scavone, M.; Visai, L.; Kenny, J.M. New Multifunctional Poly(Lactide Acid) Composites: Mechanical, Antibacterial, and Degradation Properties. J. Appl. Polym. Sci. 2012, 124, 87-98. [CrossRef]

70. Auras, R.; Lim, L.; Selke, S.E.M.; Tsuji, H. Poly(Lactic Acid): Synthesis, Structures, Properties, Processing, and Applications; John Wiley \& Sons: Hoboken, NJ, USA, 2010; p. 528.

71. Arrieta, M.P.; Fortunati, E.; Dominici, F.; Rayón, E.; López, J.; Kenny, J.M. PLA-PHB/Cellulose Based Films: Mechanical, Barrier and Disintegration Properties. Polym. Degrad. Stab. 2014, 107, 139-149. [CrossRef]

72. Lozano-Pérez, A.A.; Montalbán, M.G.; Aznar-Cervantes, S.; Cragnolini, F.; Cenis, J.L.; Víllora, G. Production of Silk Fibroin Nanoparticles using Ionic Liquids and High-Power Ultrasounds. J. Appl. Polym. Sci. 2015, 132. [CrossRef]

73. Hu, X.; Kaplan, D.; Cebe, P. Determining Beta-Sheet Crystallinity in Fibrous Proteins by Thermal Analysis and Infrared Spectroscopy. Macromolecules 2006, 39, 6161-6170. [CrossRef]

74. Bhat, N.V.; Nadiger, G.S. Crystallinity in Silk Fibers: Partial Acid Hydrolysis and Related Studies. J. Appl. Polym. Sci. 1980, 25, 921-932. [CrossRef] 